\begin{tabular}{|c|c|c} 
Eiszeitalter u. Gegenwart & $\mathbf{3 1}$ & $109-133$ \\
& & $11 \mathrm{Abb}$.
\end{tabular}

Hannover 1981

\title{
Die quartären Äolianite von Ibiza und Formentera (Balearen, Mittelmeer) und ihre Bedeutung für die Entwicklungsgeschichte der Inseln
}

\author{
Dierk Henningsen, Dieter Kelletat \& Herbert Hagn *)
}

Landform evolution, eolianite, limestone, calcareous sand, incrustation, biogene origin, Foraminifera, Continental Quarternary, marine terrace, abrasion, shoreline, island, section, sampling, index map. Balearic Island (Ibiza, Formentera)

Kurzfassung: Die auf den Balearen-Inseln Ibiza und Formentera weit verbreiteten quartären Kalksande, die bis in Höhen von $>250 \mathrm{~m}$ ü. NN vorkommen, sind ausschließlich Windsedimente (Äolianite). Sie wurden teilweise festländisch umgelagert. Die Aolianite im Westen und Norden von Ibiza enthalten Foraminiferen, die bis in das Emilianum (Spätes Altest-Pleistozän) zurückreichen. Die Kalksande wurden seit dem Emilianum in mehreren Zyklen während des älteren Pleistozäns angeweht. Die im Süden Ibizas und auf Formentera vorkommenden Aolianite stammen dagegen aus dem Jung-Pleistozän, auf Formentera ist eine Neotyrrhen-Strandterrasse in ihnen ausgebildet. An den Küsten Ibizas wurden keine herausgehobenen Strandterrassen beobachtet, die Insel zeigt bis in die Gegenwart hinein Anzeichen einer Absenkung.

\section{[Quaternary Eolianites from Ibiza and Formentera (Balearic Islands, Western Mediterranean) and their Significance for the Evolution of Both Islands]}

A bstract: The calcareous sands of Ibiza (found up to elevations of more than $250 \mathrm{~m}$ ) and Formentera are wind sediments only (eolianites). Partly they have been reworked under continental conditions. The eolianites of western and northern Ibiza contain forams dating back to the Emilian (Upper part of the Early Pleistocene). The sands have been blown upon in several cycles since the Emilian during the Lower Pleistocene. The eolianites of southern Ibiza and Formentera belong to the Upper Pleistocene, in Formentera a marine terrace of the Neotyrrhenian is developed within them. Along the coasts of Ibiza no elevated shorelines have been observed, the island shows a tendency to submerge still in the present.

\section{[Las eolianitas del Cuaternario de Ibiza y Formentera (Islas Baleares, Mediterráneo) y sus significación para el desarollo de ambas islas]}

Resumen: Las arenas calcáreas del Cuaternario que cubren una gran parte de las Islas Baleares Ibiza y Formentera se encuentran hasta alturas mayores de $250 \mathrm{~m}$ sobre el nivel del mar. Se trata exclusivamente de sedimentos de origen dunar (eolianitas) cuya posición ha sido parcialmente alterada bajo condiciones continentales. Las eolianitas del oeste y del norte de Ibiza contienen foraminíferos que alcanzan una edad Emiliense (Parte superior del Pleistoceno antiguo). Han sido acumuladas en varios ciclos durante el Pleistoceno inferior. En cambio las eolianitas del sur de Ibiza y de Formentera pertenecen al Pleistoceno superior. En Formentera, una terraza marina del Neotyrrheniense se ha formado en ellas. En las costas de Ibiza no se han observado terrazas marinas elevadas, la isla muestra señas de hundimiento hasta el presente.

*) Anschriften der Verfasser: Prof. Dr. D. H e n n in g s e n, Institut für Geologie und Paläontologie der Universität, Callinstr. 30, 3000 Hannover 1; Prof. Dr. D. K ell e t a t, Geographisches Institut der Universität, Schneiderberg 50, 3000 Hannover 1; Prof. Dr. H. H a g n, Institut für Paläontologie und historische Geologie (Abt. Mikropaläontologie) der Universität, RichardWagner-Straße 10/II, 8000 München 2. 
Inhaltsverzeichnis

1. Einleitung

2. Bisherige Literaturangaben über die Aolianite

3. Vorkommen, Verbreitung und Ausbildung der Äolianite

3.1. Altere Aolianite

3.2. Jüngere Aolianite

3.3. Subrezente bis rezente Dünenbildungen

4. Verwendung und Nutzung der Äolianite

5. Mikropaläontologische Untersuchung und Altersstellung der Gesteinsproben (H. HAGN)

6. Petrographische Zusammensetzung der Äolianite (H. Hagn \& D. Henningsen)

7. Entstehungsbedingungen der Äolianite

8. Beziehungen zwischen Morphogenese der Inseln und den Äolianiten

8.1. Fußflächen

8.2. Talformen

8.3. Schuttdecken, Böden und Bodensedimente

8.4. "Kalkkrusten“

8.5. Pleistozäne Strandterrassen und -ablagerungen

9. Entwicklungsgeschichte der Inseln im Jungpliozän und Quartär

10. Liste Probenpunkte

11. Schriftenverzeichnis

\section{Einleitung}

Weite Teile der Insel Ibiza werden von karbonatischen Äolianiten des Quartärs bedeckt. Sie sind in den letzten Jahren verstärkt abgegraben und abgebaut worden, wodurch zusätzlich zu den Küsten-Profilen mehrere größere, wenn auch oft nur kurzzeitig bestehende Aufschlüsse geschaffen wurden. Diese ermöglichen eine gezielte Bearbeitung der Gesteinsserien, die bisher in der geologischen Literatur über Ibiza nur am Rande behandelt worden sind: Sowohl über die Altersstellung als auch über die Entstehungsbedingungen der Aolianite liegen erst allgemeine Angaben vor; die Beziehungen der Äolianite zu anderen Bildungen des Quartärs auf Ibiza sind offen geblieben, die Bedeutung der Aolianite für die Rekonstruktion der Entwicklungsgeschichte der Insel im Quartär wurde noch nicht erörtert. Diese Lücken will die vorliegende Arbeit schließen.

Ausgangspunkt dieser Untersuchung sind erste Beobachtungen, die D. Henningsen im Jahre 1977 auf Ibiza machte. In zwei von ihm gesammelten Pilotproben konnte H. HAGN Foraminiferenfaunen des Altquartärs bestimmen. Mit Zustimmung der Comisión de Geólogía in Madrid erfolgten dann im Oktober 1980 die Geländeruntersuchungen auf Ibiza, in deren Verlauf auch Formentera besucht wurde, durch D. Henningsen und D. Kelletat. Diese Reise wurde durch einen Zuschuß der Hannoverschen Hochschulgemeinschaft ermöglicht, für den wir uns ausdrücklich bedanken. Die mikropaläontologische Bearbeitung der gesammelten Proben führte wieder H. HAGN durch (Kap. 5), der außerdem wesentliche Teile der sedimentpetrographischen Daten ermittelt hat (Kap. 6). Bestimmungen von Ostracoden verdanken wir Herrn Dr. H. Malz (Frankfurt).

\section{Bisherige Literaturangaben über die Äolianite}

Von Nolan (1895: 89) war auf die weite Verbreitung von sandigen und kalkigen „Schichten des Pleistozäns mit Helix “ auf Formentera hingewiesen worden, womit zweifellos die "Aolianite gemeint sind.

FALLOT (1922: $188 \mathrm{ff}$.) griff den vorher in der Literatur über Mallorca verwendeten Namen "Marès" (Spanische Schreibweise: marés) auf. Er sah die entsprechenden Ablagerungen auf Ibiza teils als Strand-, teils als Dünenbildungen an, in vielen Fällen sei das Material auch durch Flüsse umgelagert. FALLOT führte aus, daß Marés-Ablagerungen in sehr verschiedenen Höhenlagen auf- 
treten. Einige der von ihm genannten Vorkommen sind jedoch weder auf den späteren geologischen Karten (IGME 1970) verzeichnet, noch konnten sie bei der Geländearbeit der Verfasser aufgefunden werden.

Spiker \& Hanstra (1935): 28 f.), die die Insel Ibiza im Rahmen von Doktorarbeiten geologisch aufgenommen hatten, bezeichneten die Aolianite insgesamt ebenfalls als Marés. Sie stellten sie allgemein in das Quartär; im Sinne von Fallot (1922) gingen sie davon aus, daß es sich teils um Strand-, teils um Dünenablagerungen und teils um durch Flüsse umgelagertes Material handele.

Im Rahmen von detaillierten Beschreibungen verschiedener quartärer Küstenprofile von Ibiza erwähnte SolÉ SABARIS (1962) mehrfach Dünensande, die örtlich karbonatisch verfestigt sind. Er wies darauf hin (S. 312), daß die Bezeichnung Marés nur für stark zementierte Dünen- oder Meeressande üblich sei. Einen von SpIKER \& HaAnstra (1935: 29) genannten, im SW von Ibiza gelegenen Fundpunkt von Meeres-Mollusken in Sanden dieser Serie konnte er - ebenso wie wir nicht wiederfinden. Verfestigte Dünensande seien in Ibiza wie in Mallorca nach dem Paläotyrrhen und dem Eutyrrhen abgelagert worden (1962: 335).

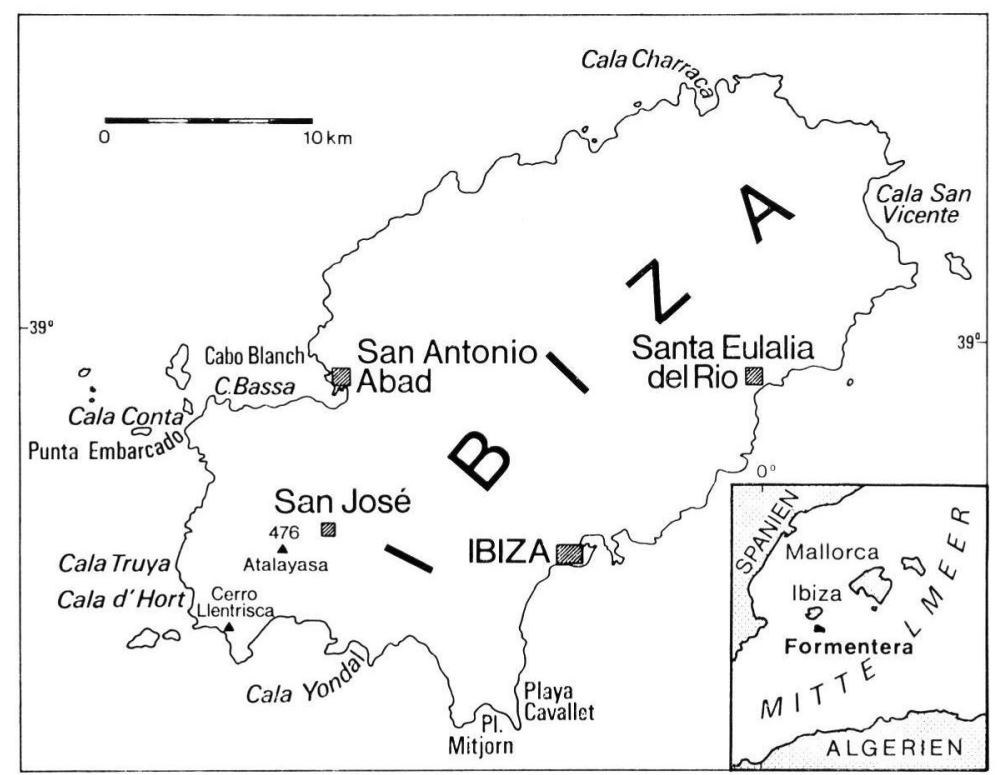

Abb. 1: Ubersichtskarte der Insel Ibiza.

Auf Rangheard (1969) gehen die Angaben in den Erläuterungen zu den geologischen Karten $1: 50000$, die Ibiza und Formentera überdecken (IGME 1970), und zur geologischen Karte $1: 200000$ zurück (IGME 1972). Im Sinne der vorhergehenden Autoren wird wieder zusammenfassend von Marés gesprochen, der teils äolisch, teils am Strand entstanden sei und sich bis in Höhen von $200 \mathrm{~m}$ verfolgen lasse. Als Alter für die genannten Ablagerungen wird nur "Quartär" angegeben. Die örtlich an den Küsten vorhandenen jüngeren Sanddünen werden nicht zum Marés gerechnet, sondern gesondert genannt.

\section{Vorkommen, Verbreitung und Ausbildung der Äolianite}

Die meist gelblich-grau, seltener leicht rötlich gefärbten Äolianite lassen sich in drei Gruppen unterteilen:

1. Teilweise verfestigte, meist deutlich gelbliche ältere Sande, die sich vor allem von den W-Küsten Ibizas in das Innere der Insel hinein verfolgen lassen und bis in größere Höhen $(>250 \mathrm{~m}$ ü. $\mathrm{NN})$ vorkommen, 
2. überwiegend verfestigte, insgesamt oft etwas heller gefärbte jüngere Sande, die im Küstenbereich vor allem im SE von Ibiza und auf Formentera verbreitet sind,

3. subrezente und rezente Dünenbildungen, die im wesentlichen durch Abtragung der beiden vorher genannten älteren Äolianite an einigen Stellen auf Ibiza und besonders auf Formentera entstanden sind.

\section{1. Ältere Äolianite}

Vorkommen von älteren Äolianiten gibt es an vielen Stellen auf Ibiza; vor allem im SW der Insel treten sie zwischen der Cala d'Hort und dem Cerro Llentrisca ebenso wie westlich von San José in zusammenhängenden Flächen von mehreren Quadratkilometern Größe auf. Weitere Hauptverbreitungsgebiete sind der W von San Antonio Abad (S der Cala Bassa bzw. der Cala des Torrent) und der südlich an die Cala Charraca im nördlichen Ibiza anschließende Bereich. In den meisten Fällen beginnen die Vorkommen an der Meeresküste und ziehen sich mit Unterbrechungen bis in höhere Lagen des Inselinneren hinauf. Die Basislagen der Äolianite sind an keiner Stelle der Küsten Ibizas aufgeschlossen, sie dürften noch einige Meter unter den heutigen Wasserspiegel herunterreichen. Dieses zeigt sich z. B. an dem isolierten Äolianit-Vorkommen an der Küste W des Cerro Llentrisca, das im unteren Teil Reste einer ehemaligen Düne erkennen läßt. In den Äolianiten befindet sich ein ausgedehnter alter Steinbruch, dessen tiefste Abbaustellen infolge junger Absenkung heute z. T. $>1 \mathrm{~m}$ unter Wasser liegen.

Das topographisch am höchsten gelegene Vorkommen von älteren Äolianiten wurde von uns am N-Hang des Cerro Llentrisca beobachtet, wo sich die in den Äolianiten angelegten Sandgruben bis zur Höhe von $260 \mathrm{~m}$ ü. $\mathrm{NN}^{1}$ ) verfolgen lassen.

Sowohl in Küstenprofilen wie auch in Aufschlüssen, die sich in höhergelegenen Tälern befinden, zeigen die unteren Lagen der Äolianite oft eine typische äolische Schräg- und Kreuzschichtung mit planaren Schüttungslamellen und Neigungswinkeln bis zu etwa $30^{\circ}$, die im Küstenbereich in der Regel landwärts einfallen.

W

$E$

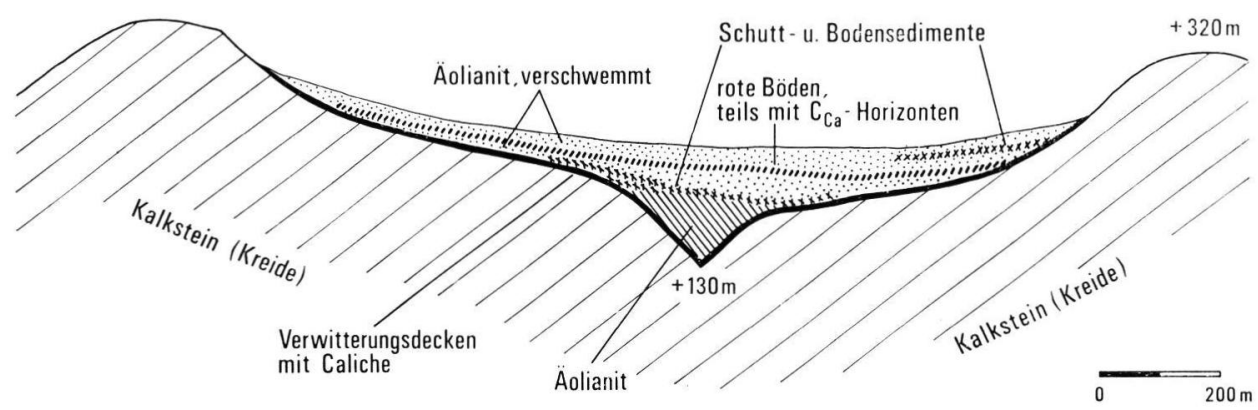

Abb. 2: Verfüllung eines Tales durch Altere Aolianite: Basispartien mit deutlicher Schrägschichtung, steil nach $\mathrm{E}$ einfallend, höhere Lagen verschwemmt und umgelagert. Große Sandgrube ca. $2 \mathrm{~km}$ W von San José.

1) Fallot (1922: 192) nannte ein Vorkommen von Marés bei San Vicente im NE-Ibiza, das in einer Höhe von 320-340 m ü. NN liegen soll. Auf Bl. San Miguel der geologischen Karte von Ibiza 1:50000 (IGME 1970) ist es jedoch nicht eingetragen und in den entsprechenden Erläuterungen nicht erwähnt. 
Üblicherweise liegen die Äolianite den mesozoischen Kalk- und Mergelsteinen, die teilweise geringfügig oberflächlich verkarstet sind, direkt auf (Abb. 2 und 4), nur gelegentlich sind zusätzlich Schuttsedimente zwischengeschaltet. In den oberen Lagen der Äolianite, die örtlich als einziges aufgeschlossen sind, liegen die Schichtungsblätter meist \pm horizontal.

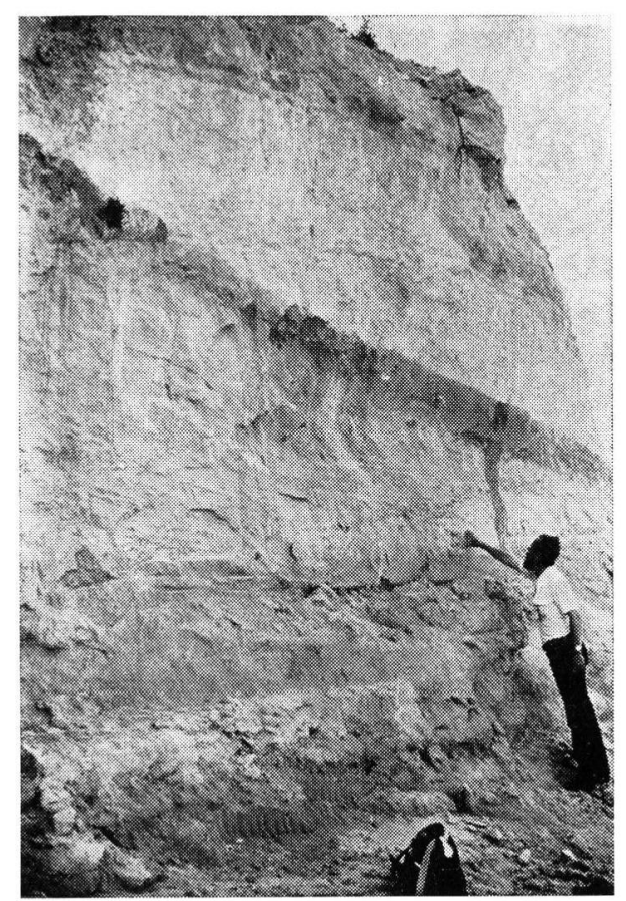

Abb. 3: Umgelagerte Partien der Alteren Äolianite mit Schuttlagen (z. B. über ausgestreckter Hand) und kräftigem Bodenhorizont (dunkel). Große Sandgrube ca. $2 \mathrm{~km}$ W von San José.

Die Aolianite sind teils locker ausgebildet, teils partienweise in unterschiedlichem Ausmaß verfestigt bzw. karbonatisch verkittet. Besonders die oberen Horizonte zeigen deutliche Korngrößenunterschiede: Neben grobsandigen Partien treten Schluff-reiche Feinsande auf, die fast Löß-artig wirken. Den sandigen Schichten der hangenden Äolianit-Folgen sind vielfach unregelmäßige Lagen oder Linsen von Grobschutt eingelagert. Sie bestehen aus Fragmenten von Kalkkrusten oder Kalkund Mergelsteinen des Mesozoikums; die einzelnen Brocken sind teils nur einige Millimeter groß, erreichen aber auch Durchmesser von mehreren Zentimetern oder sogar Dezimetern. In den Aolianiten treten vor allem in den oberen Lagen außerdem gestreckte oder gebogen-verzweigte Wurzelröhren auf, die vielfach durch Einfluß von Verwitterung oder Windausblasung deutlich hervortreten, weil sie stärker verfestigt sind und deshalb herauspräpariert werden. In einigen Aufschlüssen (z. B. große Sandgrube ca. $2 \mathrm{~km}$ W von San José, Sandgrube ca. $1 \mathrm{~km} \mathrm{SE} \mathrm{der} \mathrm{Cala} \mathrm{Bassa)}$ wurden innerhalb der oberen Lagen der Aolianite außerdem Bodenbildungen beobachtet, die teilweise in mehrfacher Wiederholung übereinander liegen: braune oder rötlich-braune Verlehmungszonen von einigen Zentimetern bis Dezimetern Mächtigkeit stellen Bodenhorizonte dar, daneben kommen auch eingeschwemmte und mit Schutt vermengte Bodensedimente vor (s. Abb. 3 und Kap. 8.3). Kleine Helix-Arten, die selten größer als $1 \mathrm{~cm}$ werden, sind als Anzeiger einer festländischen Entstehung der hangenden Äolianit-Folgen häufig zu finden.

Die Verbreitung der Alteren Äolianite auf Ibiza ist größer, als die bisherigen Karten zeigen. Es wird geschätzt, daß sie insgesamt eine Fläche von $15-20 \mathrm{~km}^{2}$ bedecken. Die Gesamtmächtigkeit der Äolianit-Folgen überschreitet vielfach den Wert von $5 \mathrm{~m}$. In der 


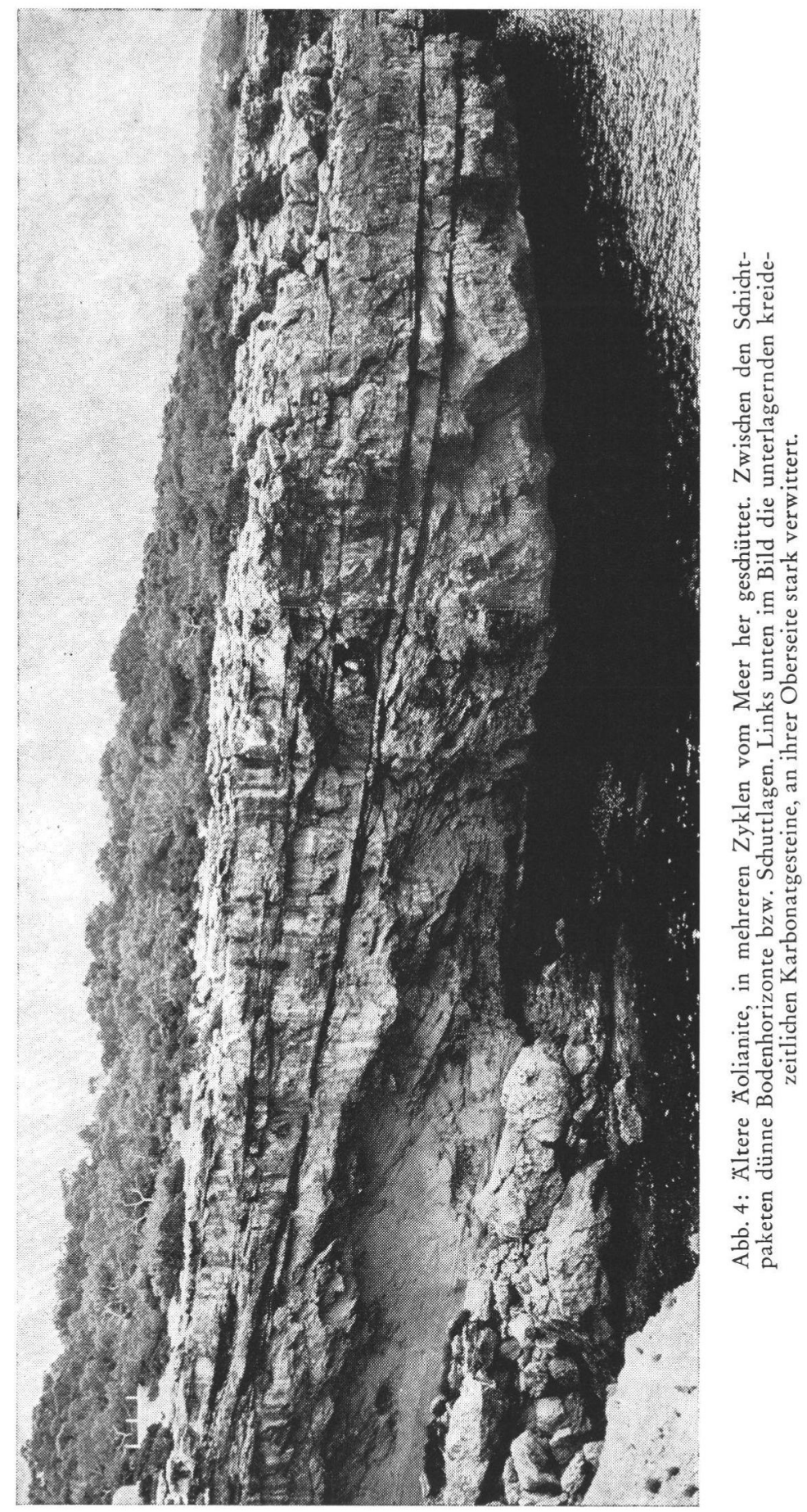


großen Sandgrube W von San José (Abb. 2) beträgt sie mehr als $25 \mathrm{~m}$. Es steht außer Zweifel, daß die meist steil schräggeschichteten Basispartien der Äolianite ausschließlich durch Winde vorherrschend westlicher Richtungen abgelagert wurden, wobei sich die Sedimente dem vorhandenen Relief anpaßten und in den Tälern vor allem an der LeeSeite angehäuft wurden. Ebenso sicher kann davon ausgegangen werden, daß die meist horizontal geschichteten höheren Lagen der Äolianit-Folgen vor allem durch Umlagerung und Verschwemmung entstanden sind, und sei es auch nur über kurze Entfernungen.

Wichtig ist, daß im Gegensatz zu den Angaben in der Literatur an keiner Stelle der Insel innerhalb der untersuchten Serien Anzeichen dafür gefunden wurden, daß diese sich teilweise im Strandbereich gebildet hätten.

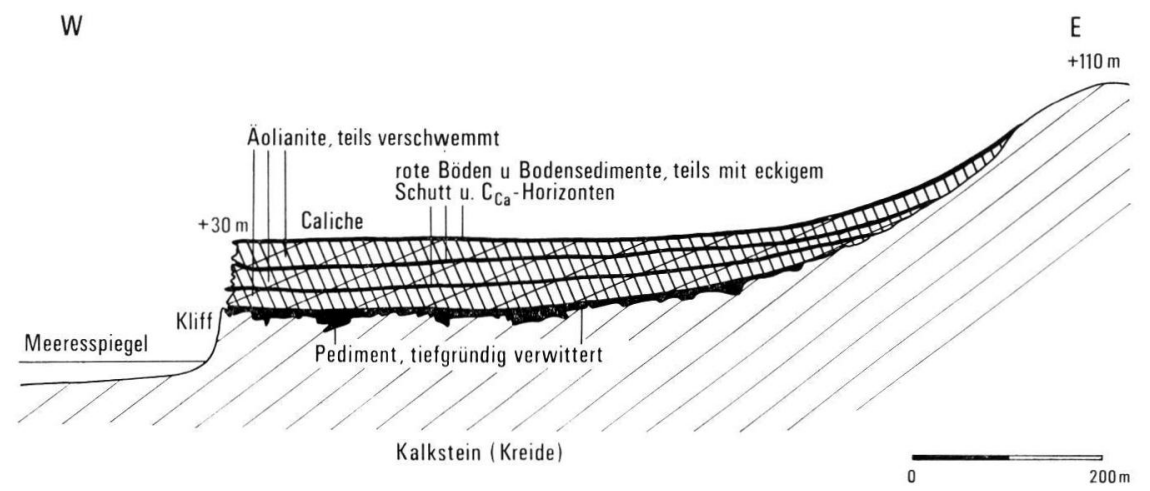

Abb. 5: Typisches Küstenprofil im westlichen Ibiza (schematisch): Uber pedimentierten und z. T. verwitterten Kalksteinen der Kreidezeit mehrere Folgen von Alteren Äolianiten, durch Bodenbildungen und Schuttlagen voneinander getrennt. An ihrer Oberseite flachlagernde Krusten. Klifflinie erheblich landwärts zurückverlegt.

Die beiden in der Literatur genannten Vorkommen von Meeresmollusken sind nicht eindeutig. Das gilt für den fraglichen Fundpunkt von Spiker \& HaAnstra (1935: 29, s. dazu Kap. 2) ebenso wie für die Angabe von Fallot (1922: 192), der von der Cala d'Hort im 90-m-Niveau „zahlreiche Pecten“ angibt. In beiden Fällen kann es sich um größere Bruchstücke gehandelt haben, die durchaus nicht gegen äolische Ablagerungen sprechen (vgl. Kap. 5).

Vergleichbare Verhältnisse liegen z. B. in Madeira vor, wo in Dünensanden bis zu $100 \mathrm{~m}$ Höhe marine Mollusken vorkommen, die offenbar hochgeweht worden sind (KrEJCI-Graf 1961: 9f.).

\subsection{Jüngere Äolianite}

Die Jüngeren Äolianite sind insgesamt gleichmäßiger und stärker verfestigt als die Alteren. Wahrscheinlich ist hierfür der Einfluß des nahegelegenen Meeres verantwortlich; denn auch in den Älteren Äolianiten herrscht im unmittelbaren Küstenbereich eine stärkere Zementierung vor, die allerdings durch nachträgliche Verwitterung und damit verbundene Auflockerung z. T. wieder aufgehoben ist.

In der Zusammensetzung sind die jüngeren Äolinite von den Älteren kaum zu unterscheiden (s. Kap. 5 und 6). Zu den jüngeren Äolianiten gehören im S-Teil von Ibiza die Serien an der Playa Mitjorn und an der dieser gegenüberliegenden Playa Es Cavallet. Außerdem werden große Teile der Insel Formentera sowie offenbar auch die zwischen Ibiza und Formentera liegenden Inseln (vor allem Espalmador) aus ihnen aufgebaut bzw. bedeckt (vgl. Nolan 1895: 89; Igme 1972: 46). 
Die jüngeren Äolianite sind an die heutigen Küstensäume gebunden. Ihre Basis liegt unter dem rezenten Meeresniveau; es ist zu vermuten, daß sie in mehreren Metern Tiefe verläuft.

Die Ausbildung an der Playa Mitjorn und der Playa Es Cavallet ist wie folgt: An der Basis sind deutlich schräg- und kreuzgeschichtete verfestigte Lagen, die teilweise starke Bioturbation erkennen lassen, in etwa $5 \mathrm{~m}$ Mächtigkeit aufgeschlossen. An mehreren Stellen befinden sich darin ehemalige Steinbrüche, die bis etwa 1-2 m unter den Wasserspiegel herunterreichen (Abb. 6 und 7). Darüber liegt diskordant ein schwach landwärts fallender rötlicher, überwiegend verfestigter sandiger Mergel (ca. $1 \mathrm{~m}$ mächtig) mit Zeichen einer Bodenbildung, darüber dann die mehrere Meter hohen subrezenten bis rezenten Dünen.

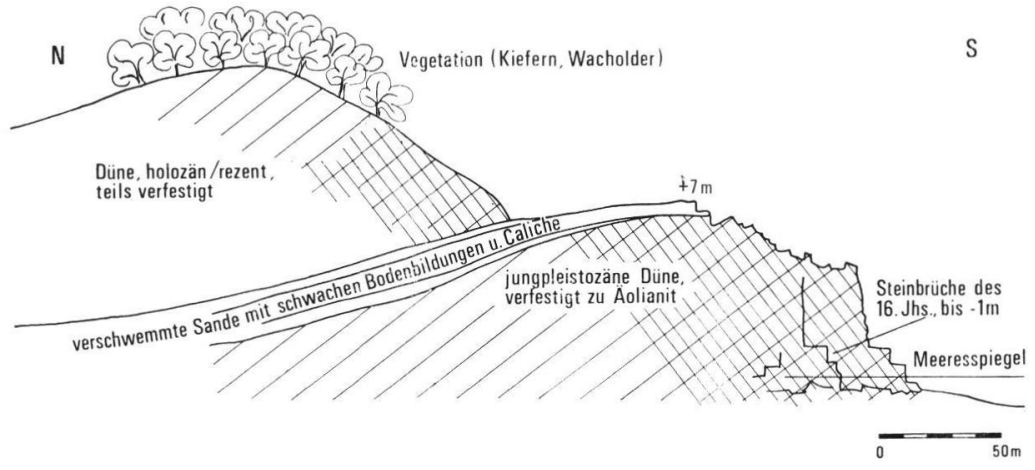

Abb. 6: Küstenprofil an der Plaja Mitjorn in S Ibiza: Uber Jüngeren Aolianiten Bodenhorizont, darüber junge Dünen. Mittelalterliche Steinbrüche bis unter den Meeresspiegel herunterreichend.

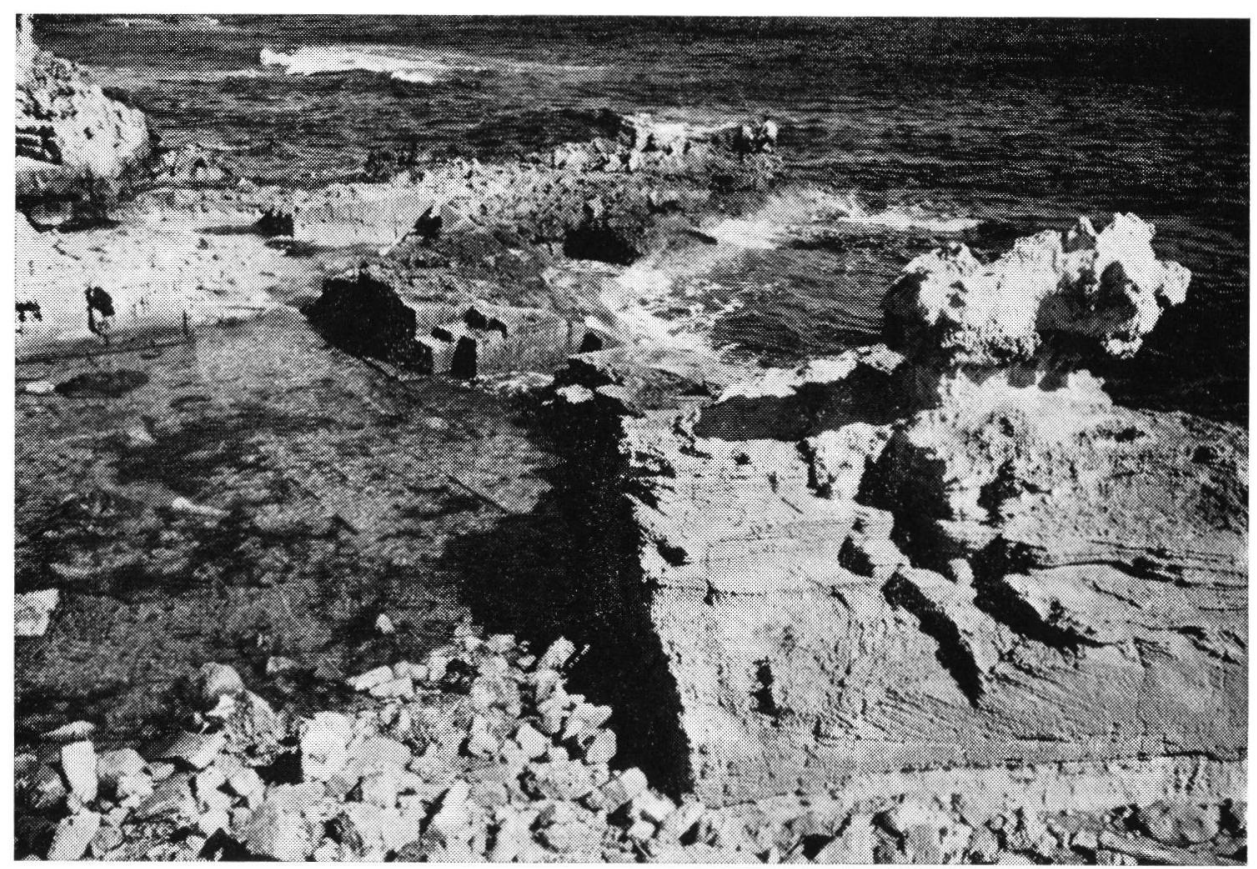

Abb. 7: Mittelalterlicher Steinbruch in Jüngeren Äolianiten, teilweise unter dem heutigen Meeresspiegel. In Bildmitte oben Angler als Größenmaßstab. Playa Es Cavallet in S Ibiza. 
An der W-Küste der südlich von Ibiza gelegenen Insel Espalmador ist die Folge der Jüngeren Aolianite durch mindestens drei deutlich ausgebildete Böden unterteilt. Im Mittelteil der Insel Formentera erreichten die Äolianite bei Es Caló am Stau vor dem südöstlichen Kalkplateau (La Mola) mehr als $60 \mathrm{~m}$ Höhe; auch hier sind in den unteren Partien häufig steil einfallende äolische Schrägschichtungen zu erkennen, während in den oberen Lagen mehrere Pakete mit Schuttlagen, dünnen Kalkkrusten und Bodenhorizonten übereinandergestapelt sind. Ahnliche Verhältnisse finden sich am SE-Rand von Formentera bei El Ram. Auffällig ist hier - ebenso wie an der Cala Envasté, die bei San Fernando an der E-Küste liegt - die starke braune bis schwarz-braune Färbung (?Humusanreicherung) der Bodenhorizonte (tirsoide Bildungen). E von El Ram steigt in südöstlicher Richtung innerhalb der Äolianit-Folge allmählich eine frühere Terrassenfläche bis auf ca. $3 \mathrm{~m}$ ü. NN heraus, die oberflächlich stark korrodiert ist und eine reiche Molluskenfauna des Neotyrrhens führt (s. Abb. 10, 11 und Kap. 8.5).

Die Abfolge der Jüngeren Äolianite entspricht insofern derjenigen der Alteren, als in den unteren Partien gleichmäßige Ablagerung durch Wind vorherrschte, danach aber längere Ruhepausen mit dazwischenliegenden Bodenbildungen die Sedimentation unterbrochen haben. Während bei den Älteren Äolianiten in dieser zweiten Phase steile Schrägschichtungen kaum noch vorkommen, also Verschwemmungen dominieren, treten in den oberen Partien der Jüngeren Äolianite mehrfach deutlich windabgelagerte Pakete mit entsprechender Schräg- und Kreuzschichtung auf.

\subsection{Subrezente bis rezente Dünenbildungen}

Subrezente bis rezente Dünen, die bis zu mehreren Metern Höhe aufgehäuft sind, kommen an einigen Stellen von Ibiza im Strandbereich vor (z. B. an der Cala Conta im NW der Insel sowie an der Playa Mitjorn und der Playa Es Cavallet im SE); außerdem besonders im Mittelteil von Formentera. Die Dünen sind teilweise bewachsen; an der Playa Mitjorn zeigen sie teils etwa horizontale, teils flach meerwärts einfallende Schrägschichtung (Abb. 6). Die Dünensande sind nur gelegentlich leicht verfestigt.

Der überwiegende Anteil des Materials, aus dem sie aufgebaut sind, besteht aus umgelagerten Alteren oder Jüngeren Äolianiten der unmittelbaren Umgebung, sei es durch direkte Ausblasung oder dadurch, daß diese vom Meer aufgearbeitet und in Form von rezenten Strandsanden wieder zur Verfügung gestellt werden.

\section{Verwendung und Nutzung der Äolianite}

Die leicht zu behauenden verfestigten Partien der Äolianite sind schon früh als Baumaterial verwendet worden; man kennt z. B. schon vor Christi Geburt in der karthagischen Zeit daraus gefertigte Särge, wie sie im Archäologischen Museum von Ibiza ausgestellt sind. Behauene Blöcke aus verfestigten Äolianiten sind, neben Kreide-Kalksteinen, als Baumaterial für die Mauern und Gebäude der Festung bzw. Altstadt von Ibiza verwendet worden; ebenso für mehrere der auf der Insel vorhandenen Wachttürme. Diese Bauwerke stammen aus dem 16. und 17. Jahrhundert; es ist anzunehmen, daß die Steinbrüche, in denen die Blöcke herausgesägt wurden, hauptsächlich in dieser Zeit in Betrieb waren (Abb. 7). Sie liegen meist im S der Insel Ibiza (W Cerro Llentrisca, Playa Mitjorn, Playa Es Cavallet). Es wurden überwiegend Jüngere Äolianite abgebaut.

Auf Formentera befindet sich in Pujols ein großer, nicht unmittelbar am Strand gelegener Steinbruch, in dem man ebenfalls verfestigte Jüngere Äolianite als Bausteine heraussägt.

Die lockeren Partien der Alteren Aiolianite, auf Ibiza als „arena“ (Sand) bezeichnet, werden seit längerem als Bausand verwendet. Daneben beutzt man die Sande in den letzten Jahren, um in Felsbuchten künstliche Strände aufzuschütten — viele der auf Ibiza vorhandenen Badebuchten sind auf diese Weise entstanden. Der Sandverbrauch für die 
Erhaltung dieser künstlichen Strände ist enorm. Die Flächen, in denen ein Abbau der Alteren Äolianite erfolgt, sind deshalb in den letzten 5 Jahren um ein Vielfaches angewachsen.

\title{
5. Mikropaläontologische Untersuchung und Altersstellung der Gesteinsproben
}

\author{
(H. HAGN)
}

Für die mikropaläontologische Auswertung standen 14 Schlämmproben von der Insel Ibiza und 2 Proben von der Insel Formentera zur Verfügung (vgl. hierzu Liste in Kap. 10). Ferner wurden 2 Schlämmproben von Ibiza berücksichtigt, die der Verfasser im September 1978 von D. HeNNINGSEN erhielt.

Die Schlämmrückstände der einzelnen Proben enthalten folgende F a un en - und Florenelemente:

Probe 1: Die reiche Fauna setzt sich aus Foraminiferen, Bryozoen, Kleingastropoden und Echinodermenresten zusammen. Die Flora wird durch Corallinaceen vertreten.

Von Sandschalern sind vor allem Textularia sagittula Defrance und Dorotbia pseudotrochus (Cushman) zu nennen. Milioliden treten in großer Zahl auf; namentlich sei vor allem Quinqueloculina longirostra D'Orв. hervorgehoben. Das Faunenbild wird hauptsächlich von den Arten Elphidium crispum (L.), E. macellum (F. \& M.), E. complanatum (D’Orв.), Ammonia beccarii (L.), A. inflata (Seguenza) und Cibicides lobatulus (W. \& J.) geprägt. Daneben wurden die Gattung Robulus sowie die Arten Astacolus crepidulus (F. \& M.), Bulimina etnea SEguenza, B. gibba Fornasini, Melonis pompilioides (F. \& M.), Neoconorbina terquemi (RzeHak), Glabratella opercularis (D’Orв.), Discorbinella sp., Asterigerinata mamilla (WILl.), Cibicides refulgens MonTF., Globocassidulina oblonga (Reuss) und Sphaerogypsina globulus (Reuss) beobachtet.

Probe 3 a: Diese Probe lieferte die reichste Foraminiferenfauna. Sie birgt folgende Gattungen und Arten:

Textularia sagittula Derfrance

Dorothia pseudotrochus (Cushman)

Quinaueloculina longirostra D'ORB.

Miliolidae (indet.)

Globulina gibba myristiformis (WILL.)

Bulimina etnea SEgUENZA

Bulimina gibba FoRNASINI (= B. fusiformis

WILL. auctorum)

Buliminella cf. elegans (D’ORB.)

Bolivina cf. catanensis SEguenza

Melonis pompilioides (F. \& M.)

Elphidium crispum (L.)

Elphidium macellum (F. \& M.)

Elphidium complanatum (D'ORв.)

Rosalina globularis D'ORB.

Die Gehäuse der Foraminiferen sind überwiegend sehr gut erhalten. Dies betrifft vor allem die pelagischen Formen (Globigerina, Globigerinoides, Globorotalia), die nur in beschränkter Individuenzahl auftreten. Das Faunenbild wird auch in dieser Probe durch die Gattungen Elphidium, Ammonia und Cibicides beherrscht.

Daneben stellen sich wie in Probe 1 reichlich Bryozoen, Kleingastropoden, Echinidenreste sowie Schutt von Rotalgen (Corallinaceen) ein.

In den beiden bereits früher aufgesammelten Proben I und II wurden zusätzlich noch folgende Foraminiferen-Arten gefunden: Bulimina costata D'Orb., Reussella sp., Eponides repandus (F. \& M.), Planorbulina mediterranensis D'Orв., Gypsina sD. und Globigerina bulloides D'ORB. Beide Proben führen darüber hinaus Globigerinoides tenellus PARKER und Globorotalia inflata (D’Orв.). Selbst Ostracoden fehlen nicht. Nach einer brieflichen Mitteilung von Herrn Dr. H. Malz, Frankfurt a. M., liegen die Arten Falunia (Hiltermannicythere) cephalonica UliczNY, Caudites calceolatus (Costa) und Aurila sp., ex. gr. punctata (MüNSTER) vor.

2) Ein Vergleich der vorliegenden Gehäuse mit rezentem Material von Globigerinoides tenellus Parker (Straße von Mozambique und Südatlantik), das Herr Dr. E. Boltovskoy, Buenos Aires, freundlicherweise zur Verfügung stellte, erbrachte keine völlige Ưbereinstimmung. Ein großer Teil der Gehäuse gehört vielmehr zu Gl. ruber (D’Orв.). 
Probe 4 a : Die mäßig reiche, ziemlich eintönige Foraminiferenfauna setzt sich im wesentlichen aus Milioliden sowie aus Angehörigen der Gattungen Elphidium, Ammonia und Cibicides zusammen. Kleingastropoden, Echinidenreste und Corallinaceen ergänzen das faunistische und floristische Bild.

Die Fauna läßt nur eine sehr geringe Diversität erkennen. Die Biogene erscheinen stark abgeschliffen. Feinste Kalzitbeläge an der Oberfläche verleihen ihnen bisweilen einen schimmernden Glanz.

Probe 4b: Auch die Fauna dieser Probe zeichnet sich durch eine ziemlich schlechte Erhaltung aus. Die meisten Gehäuse sind stark abgeschliffen. Neben den Ubiquisten Elphidium und Ammonia konnten die Arten Rosalina globularis D'OrB., Glabratella opercularis (D'ORB.), Cibicides refulgens MonTF. und Globorotalia inflata (D'OrB.) beobachtet werden. An Ostracoden wurden mit Vorbehalt Urocythereis sp. juv. und Aurila convexa emathiae UliczNy (det. H. Malz) bestimmt.

Probe 6: Die Faunenelemente dieser Probe (Schuttsediment, vgl. Kap. 8.3) fallen aus dem bisherigen Rahmen. Sie sind aus Kreide und Jungtertiär umgelagert. Die Gehäuse sind daher sehr schlecht erhalten und erscheinen kreidig-weiß.

Aus der Mittelkreide liegen umgelagerte Orbitolinen vor. Der Oberkreide sind folgende Gattungen und Arten zuzurechnen: Globotruncana lapparenti Brotzen, Gl. arca (CusHman), Gl.fornicata Plummer, Hedbergella, Gavelinella, Stensioeina und Dorothia. Aus dem J ungtertiär stammen Sandschaler (Rhabdammina, Trochammina) sowie die kalkschaligen Gattungen Nodosaria, Stilostomella, Elphidium, Rosalina, Eponides, Siphonina, Ammonia, Anomalinoides und Globorotalia.

Probe 6a: Diese Probe entspricht im wesentlichen der Probe 6. Als ältestes Faunenelement konnte die Gattung ? Simplorbitolina nachgewiesen werden. Aus der höheren Oberkreide (Zeitbereich Obercampan - Maastricht) stammen ein- und zweikielige Globotruncanen sowie die Gattungen Hedbergella, Globigerinelloides, Lenticulina, Coryphostoma, Stilostomella, Gyroidina und Stensioeina. Das Jungtertiär wird durch schlecht erhaltene Gehäuse von Elphidium, Cibicides und Globigerina vertreten.

Probe 7 : Die Fauna dieser Probe schließt eng an die Faunengemeinschaften der Proben 1 und $3 \mathrm{a}$ an. Sie läßt wiederum eine größere Diversität erkennen. Die Gehäuse sind gut bis mäßig gut erhalten und erscheinen nur wenig abgeschliffen. Es wurden folgende Gattungen und Arten ermittelt:

Dorothia pseudotrochus (Cushman)

Quinqueloculina longirostra D'ORB.

Triloculina tricarinata D'ORB.

Globulina gibba D'OrB.

Elphidium crispum (L.)

Elphidium macellum (F. \& M.)

Elphidium complanatum (D'ORB.)

Rosalina globularis D'ORB.

Glabratella opercularis (D’ORB.)

Asterigerinata sp.

\author{
Cancris auriculus (F. \& M.) \\ Ammonia beccarii (L.) \\ Ammonia inflata (SEGUENZA) \\ Cibicides lobatulus (W. \& J.) \\ Cibicides refulgens MonTF. \\ Cibicidella variabilis (D’ORB.) \\ Cassidulina carinata SILVESTRI \\ Globocassidulina oblonga (REUss) \\ Sphaerogypsina globulus (REuss) \\ Globorotalia inflata (D’ORB.)
}

Daneben wurden wiederum zahlreiche Bryozoen, Kleingastropoden und Echinidenstacheln angetroffen.

Probe 11 : Die Biogene dieser Probe sind stark abgeschliffen. Der Artenbestand ist bedeutend geringer als derjenige der vorhergehenden Probe. Neben den konventionellen Milioliden, Elphidien und Ammonien konnten Glabratella opercularis (D'OrB.) und Cibicidoides psendoungerianus (Cushman) bestimmt werden. Ferner wurden reichlich Spirorben, Bryozoen, Kleingastropoden, rötliche Echinidenstacheln sowie Corallinaceen beobachtet.

Probe 14: Die reiche Fauna setzt sich aus nur verhältnismäßig wenigen Gattungen und Arten zusammen. Es wurden bestimmt: Dorothia pseudotrochus (Cushman), Miliolidae (Quinqueloculina, Triloculina, Pyrgo), Elphidium crispum (L.), E. macellum (F. \& M.), E. complanatum (D’Orв.), Discorbina cf. mira (Cushman), Neoeponides haidingerii (D’Orв.), Cibicides lobatulus (W. \& J.), C. cf. refulgens MonTF., C. psendoungerianus (Cushman) und Sphaerogypsina globulus (Reuss). Daneben wurde eine aus der Kreide umgelagerte Orbitolina beobachtet. Bryozoen, Annelidenröhren, Kleingastropoden (u. a. Cerithien) nehmen maßgeblich an der Zusammensetzung der Fauna teil.

P rob e 15: Es liegt eine reiche, großwüchsige, aber eintönige Fauna vor. Die Gehäuse tragen häufig eine dünne Kalzithülle. Die Elphidien sind nicht selten median gespalten. 
Neben Dorothia pseudotrochus (Cushman) wurden Milioliden (darunter auch die Gattung Spiroloculina), Elphidium, Ammonia und Cibicides gefunden. Daneben treten Steinkerne von Kleingastropoden und rötliche Echinidenstacheln auf.

Probe 16: Die vorliegende Fauna entspricht in allen Punkten derjenigen der Probe 15. Die Gehäuse erscheinen infolge sekundärer Kalzitanlagerung manchmal wie überzuckert. Die Elphidien sind häufig median gespalten. Die indifferente Fauna setzt sich aus Milioliden, Elphidien, Discorbina, Cibicides sowie aus Spirorben, Bryozoen und Echinodermenschutt zusammen. An Ostracoden konnte mit Vorbehalt Urocythereis margaritifera (G. W. MüLLER) erkannt werden (det. H. MALz). Corallinaceen sind häufig.

Probe 21: Diese Probe lieferte nur eine spärliche, etwas kleinwüchsige und schlecht erhaltene Fauna. Ihre Zusammensetzung weist keine Besonderheiten auf und beschränkt sich auf Milioliden, Elphidien, Ammonien, Cibicides, Kleingastropoden und Echinidenstacheln.

Proben 22 und 22 b: Die beiden Proben bergen eine artenarme, ziemlich schlecht erhaltene Fauna und Flora. Die Biogene sind teilweise außerordentlich stark abgeschliffen; nicht selten wurde durch den Abrieb selbst der Steinkern freigelegt. Die Foraminiferen verteilen sich wiederum auf Milioliden, Elphidien und Ammonien. Namentlich seien noch Rosalina globularis D'OrbB., Discorbina cf. mira (Cushman) und Cibicides lobatulus (W. \& J.) hervorgehoben. In den Schlämmrückständen treten sehr häufig Spirorben, Annelidenröhren, Kleingastropoden und -lamellibranchiaten, Echinodermenreste sowie Corallinaceen auf. An Ostracoden wurde eine fragliche Urocythereis sororcula (Seguenza) entdeckt (det. H. Malz). Auffallend sind zahlreiche O o id e und walzenförmige Gebilde, die sich im Dünnschliff als Krebs-Koprolithen entpuppten (S. 123).

Probe 25 : Die reiche, großwüchsige und verhältnismäßig gut erhaltene Fauna beinhaltet folgende Gattungen und Arten:

Dorothia pseudotrochus (CusHMAN) Quinqueloculina longirostra D'OrB. Miliolidae (Pyrgo, Triloculina, Quinqueloculina, Spiroloculina) Amphisorus hemprichii EHRENBERG Globulina gibba D'OrB.

Elphidium crispum (L.)

Elphidium macellum (F. \& M.)
Elphidium complanatum (D'Orв.)

Rosalina globularis D'OrB.

Discorbina cf. mira (Cushman)

Discorbinella sp.

Ammonia beccarii (L.)

Cibicides lobatulus (W. \& J.)

Cibicides refulgens MontF.

Globorotalia crassaformis (GALLOWAy \& WisSLER)

Wie in allen übrigen Proben beteiligen sich auch hier Bryozoen, Kleingastropoden und Echinidenstacheln an der Zusammensetzung der Fauna. Die wenigen Ostracoden verteilen sich auf Aurila woodwardii (BRADY), Quadracythere (Tenedocythere) prava (BAIRD) und ?Urocythereis sp. (det. H. Malz).

Probe 25 a: Die Fauna ähnelt derjenigen der vorhergehenden Probe. Sie ist aber artenärmer, außerdem sind ihre Biogene stärker abgeschliffen.

Die Altersbestimmung der vorliegenden Proben wird durch den vorherrschenden litoralen Faziescharakter der umgelagerten Biogene und durch das dadurch bedingte Zurücktreten bzw. Fehlen pelagischer Foraminiferen erschwert. Es ist ferner zu berücksichtigen, daß ein großer Teil der angetroffenen Faunenelemente eine sehr weite Vertikalverbreitung besitzt. Zu diesen Durchläufern gehören vor allem die Milioliden, Elphidien, Ammonien und die meisten Cibicides-Arten. Einige Foraminiferen sind Nachzügler aus dem Jungtertiär wie z. B. Globorotalia inflata (D'Orв.).

Zunächst kann Pliozän mit aller Sicherheit ausgeschlossen werden. Nach RugGIERI \& SProvieri (1977: 134) setzen im Quartär die Foraminiferenarten Bulimina etnea SEguenza und Globigerinoides tenellus Parker ein (vgl. hierzu Colalongo, Cremonini \& SARTONi 1978: 74-75). Beide Arten wurden in der Probe 3 a sowie in den beiden früheren Proben von Cala d'Hort (S.118) nachgewiesen. Damit können diese Äolianite in das $\mathrm{Ple}$ is to zän eingestuft werden. Freilich gelang es nicht, das Hauptleitfossil Hyalinea baltbica (Schroeter), einen klassischen Kälteanzeiger, aufzufinden. Dieser Nachweis glückte aber auch Mateu, Colom \& Cuerda (1979: 61) nicht, denen eine mikropaläontologische Bearbeitung des Altpleistozäns der Insel Cabrera S Mallorca zu verdanken ist. 
Die Schichten mit Globorotalia inflata (D’ORв.) können ferner in das ä 1 t e r e Pleistozän gestellt werden. In ihnen tritt Globorotalia truncatulinoides (D'ORв.) noch nicht auf. Da die genannte Art nach Ruggieri \& Sprovieri (1977: Fig. 2 auf S. 134) erst ab dem Siciliense vorkommt, bleiben für eine Altersbestimmung nur die beiden ältesten Stufen des Pleistozäns, das Santerniense und das Emiliense, übrig. In diesem Zusammenhang ist von Interesse, daß Mateu, Colom \& Cuerda (1979: 52 ff.) aus gleichartigen Äolianiten von Cabrera eine Mikrofauna beschrieben, die mit den Faunengemeinschaften unserer Proben 1, 3a und 7 eine große Übereinstimmung zeigen. Ein sehr bezeichnendes gemeinsames Fossil ist z. B. Glabratella opercularis (D’Orb.). Die Äolianite von Cabrera wurden von den genannten Autoren in das Emilia num gestellt (MATeu, Colom \& Cuerda 1979: 64).

Ein Vergleich der vorliegenden Proben mit dem italienischen Altquartär (z. B. LentinI 1971: 149 ff.) wird durch die Artenarmut der spanischen Äolianite erschwert. Sie lassen sich weder mit der Globigerina pachyderma-Zone noch mit der Hyalinea baltbica-Zone mit Sicherheit korrelieren (vgl. hierzu Colalongo 1968: 45 ff.; D’Onofrio 1968: 109 ff.). Es erscheint daher gerechtfertigt, wenigstens vorerst die Einstufung der genannten spanischen Autoren in das Emilianum zu übernehmen.

Auf Grund der mit den Proben 1, 3a und 7 weitgehend übereinstimmenden Faunen können auch die Proben $4 b$ und 11 in das Emilianum gestellt werden. Die Faunen der Proben $4 \mathrm{a}, 14,15,16$ und 21 reichen für eine derartige Einstufung allerdings nicht aus. Ihre einheitliche petrographische Beschaffenheit macht aber ebenfalls ein al t qua r t är es Alter wahrscheinlich.

Wie gezeigt wurde, sind die Proben 22, 22b, 25 und 25a durch markante faunistische und lithologische Merkmale (Krebs-Pellets, Ooide) eng miteinander verbunden. Für die genannten Proben wurde bereits im Gelände ein jungpleistozänes Alter angenommen. In Probe 25 spricht Amphisorus hemprichii EHrenberg durchaus für diese Ansicht. Ferner wird in ihr die altquartäre Globorotalia inflata (D'ORB.) durch Gl. crassaformis (GALIOWAY \& Wissler) ersetzt. Man ist daher berechtigt, alle diese Proben miteinander zu korrelieren und sie in das $\mathrm{Ju} \mathrm{n} \mathrm{g}$ p 1 e is to z ä n zu stellen.

Abschließend sei noch auf ein Phänomen aufmerksam gemacht, das ausschließlich an die Aiolianite gebunden ist. So hat sich gezeigt, daß die orographisch höchstgelegenen Flugsande (z. B. Probe $3 \mathrm{a}, 250 \mathrm{~m}$ über NN) die meisten pelagischen Foraminiferen führt, die ja offenes Meer anzeigen. Desgleichen weisen die Angehörigen der Familie der Buliminidae (Bulimina, Buliminella, Bolivina) in derselben Probe auf eine etwas größere Wassertiefe hin, als sie für die meisten anderen Proben anzunehmen ist. Man gewinnt daher den Eindruck, daß die Proben einen um so litoraleren Faziescharakter annehmen, je orographisch tiefer sie entnommen wurden.

Hier bieten sich zwei Möglichkeiten der Erklärung an. Einmal könnte dieser Befund stratigraphisch gedeutet werden, vorausgesetzt, das STENo'sche Gesetz der Superposition ist auch auf Äolianite anwendbar. In diesem Fall wäre die Probe 3 a den jüngsten altquartären Dünenbildungen entnommen. Man könnte sich durchaus vorstellen, daß bei einer fortschreitenden Regression des Meeres in einer Kaltzeit immer tiefere Meeresgründe um die Insel trockengelegt und vom Wind ausgeblasen wurden. Daraus folgt, daß pelagische Foraminiferen und Bewohner des äußeren Schelfs erst sehr spät in einem Dünenprofil erscheinen können.

Die zweite mögliche Deutung beruht auf dem Prinzip der Windsichtung. Die gröberen und schwereren Partikel fallen zuerst zu Boden, während der feinste „Schweb“, also die zarteren Gehäuse, einen größeren Weg zurücklegen und so bis auf die größten Höhen gelangen können. In der Tat ist die orographisch höchste Probe 3 a auch die feinkörnigste. Sie enthält überwiegend Biogene, während die Lithoklaste stärker in den Hintergrund treten.

Es bedarf noch einiger Überlegungen und Beobachtungen im Gelände, um sich für die eine oder andere der aufgezeigten Deutungsmöglichkeiten entscheiden zu können. 


\title{
6. Petrographische Zusammensetzung der Äolianite
}

\author{
(H. Hagn \& D. Henningsen)
}

Wesentliche, wenn auch nur knappe Angaben über die petrographische Zusammensetzung der Äolianite sind schon von früheren Autoren gemacht worden (besonders SPIKER \& HaAnstra 1935: 28 f.; Rangheard in Igme 1970). Es handelt sich überwiegend um Mittel- und Grobsande (Korndurchmesser meist zwischen $0.1-1 \mathrm{~mm}$, gelegentlich erreichen die Körner die Größen von 5-10 mm). Fossilreste und -bruchstücke sind bis zu $2 \mathrm{~cm}$ und mehr groß. Die Proben sind teils gut, teils schlecht klassiert; der Rundungsgrad der einzelnen Körner/Partikel ist unterschiedlich, überwiegend aber mäßig bis gut. Von 15 Proben wurde jeweils ein kleiner Teil des Schlämmrückstandes (Fraktion zwischen 0,1 und $1 \mathrm{~mm}$ ) in Kunstharz (Akemi) eingegossen und von den so entstandenen Harzkuchen $\mathrm{D}$ ün nschliffe angefertigt. Auf diese Weise konnte die Herkunft der anorganischen Bestandteile (Lithoklaste) geklärt werden.

Im Dünnschliff zeigte sich, daß die Proben 1, 3a, 4a, 4b, 7, 11, 14, 15, 16 und 21 gemeinsame Merkmale aufweisen. Das Verhältnis zwischen Lithoklasten und Biogenen ist zwar gewissen Schwankungen unterworfen, doch konnten keine qualitativen Unterschiede in der Zusammensetzung der einzelnen Proben festgestellt werden. Die an Biogenen reichste Probe ist Probe 3a, während die Proben $4 a$, $4 b$ und 7 den größten Gehalt an Lithoklasten aufweisen.

Die L i th ok 1 a s t e n sind durchwegs gut gerundet. In stärker verkitteten Proben beobachtet man an ihrer Oberfläche feinste Kalzitkriställchen. Die meisten Komponenten sind zweifellos auf oberkretazische Gesteine zu beziehen. Mikrite mit Hedbergella, Rugoglobigerina, Globotruncana, Globigerinelloides, Heterobelix und Calcisphaeren herrschen bei weitem vor. Von der äolischen Umlagerung wurden daher vor allem pelagische Faziesbereiche erfaßt. Graue Miliolidenkalke sind hingegen wohl aus der Un te r k r e id e abzuleiten. Daneben wurden graue fossilleere Mikrite und körnige Karbonate, wohl Dolomite, beobachtet, die sich einer genaueren Beurteilung entziehen. In weit geringerem Umfang konnten te rtiär e Komponenten, z. T. mit grobporigen Globigerinen, nachgewiesen werden. Hierher sind wohl auch feinsandige Gesteinsbröckchen zu rechnen. In Probe 1 wurde zudem ein Geröllchen eines Caliche-artigen Gesteins festgestellt, das als feinwelliger Süßwasserkalk ausgebildet ist. Quarz tritt in allen Proben nur sehr selten in Form isolierter Körner auf (s. u.). Oft ist dieses Mineral in Lithoklasten eingeschlossen.

Unter den B i o g e n e n spielen Foraminiferen eine große Rolle. Sandschaler (Textularia, Dorothia), Porzellanschaler (Milioliden, Nubecularia) und Kalkschalig-Perforierte (Elphidium, Ammonia, Cibicides und andere rotaliide Formen) wurden allenthalben angetroffen. Auch Planorbulina und Sphaerogypsina globulus (REUss) stellen sich gelegentlich ein. In Probe 3a konnten selbst die Gattungen Bulimina und Globorotalia erkannt werden. Die Probe 1 lieferte darüber hinaus noch eine aus der Mittelkreide umgelagerte Orbitolina.

Die Metazoen verteilen sich auf Bryozoen, Anneliden (Spirorbis, Ditrupa), Mollusken (häufig mit wohlerhaltener Kreuzlamellenstruktur) sowie auf Echinodermen mit deutlich erkennbarer Siebstruktur. Die Schalenreste von Mollusken zeigen sich häufig von Thallophyten angebohrt.

Rotalgen aus der Familie der Corallinaceae treten fast in jedem Schliff sehr häufig auf. Artikulate Gattungen aus der Unterfamilie der Corallineae (Jania, Corallina, Amphiroa) herrschen bei weitem vor. Daneben wurden Angehörige der Unterfamilie Melobesideae (Lithophyllum, Lithoporella und Archaeolithothamnium) beobachtet. 
Eine Besonderheit bieten die Dünnschliffe der Proben 22, 22b, 25 und 25a. In ihnen wurden, teilweise in großer Häufigkeit, echte O o ide festgestellt. Die Zahl der Kugelschalen ist z. T. sehr groß. Als Kern der Ooide dienten häufig Fossilreste (z. B. Elphidien, Echinodermenreste). Im polarisierten Licht ist ein schwarzes Achsenkreuz zu erkennen, wodurch ein sphärolithischer Aufbau angezeigt wird. Daneben kommen zahlreiche K o p rolithen von Krebsen aus der Gruppe der Thalassinoidea (Unterordnung Anomura), also echte Pellets, vor. Ihre Internstruktur erinnert in fast allen Einzelheiten an diejenige der Gattung Favreina aus den Jura-Kreide-Grenzschichten. Bezeichnend ist ferner das starke Zurücktreten der Kreidekomponenten in allen vier Schliffen.

Nach einer Weglösung der Kalkkomponenten wurden in Aolianit-Proben folgende Nebengemengteile bestimmt: überwiegend Quarz (eckige Körner) sowie Einzelkörner von Plagioklas, Glaukonit, Erz, Zirkon, Turmalin und ?Staurolith. Außerdem sind kleine Fragmente von Tonsteinen sowie phosphatische organische Reste vorhanden. Die nichtkarbonatischen Körner haben insgesamt - wie in einem äolischen Sediment üblich ist kleinere Korndurchmesser als die Karbonat-Körner aus derselben Probe.

Die Verfestigung der Äolianite wird durch feinkörnigen Granular-Zement an den Berührungsstellen der Körner/Partikel bewirkt. Die Hohlräume zwischen diesen bleiben dabei weitgehend frei.

\section{Entstehungsbedingungen der Äolianite}

Die Entstehung der ausgedehnten Vorkommen von Äolianiten auf Ibiza und Formentera wird verständlich, wenn man berücksichtigt, daß folgende Voraussetzungen dafür vorgelegen haben:

Trockenfallen von ausgedehnten Flachwasser-Gebieten: Der Bildungsbereich der meisten Organismen, aus deren Resten sich die Äolianite zusammensetzen, ist das Flachwasser (Litoral und Sublitoral).

Tiefenlinienkarten des westlichen Mittelmeeres zeigen im W von Ibiza und Formentera relativ breite Schelfgebiete. Bei entsprechender Absenkung des Meeresspiegels infolge Regression oder Heraushebung der Inseln ständen weite Bereiche zur Verfügung, aus denen durch westliche Winde organische und anorganische kalkige Reste in großen Mengen ausgeweht und auf die Inseln verblasen werden könnten. Dabei ist während der Bildung der Alteren Äolianite die Zeitdauer der Meeresspiegel-Senkung und Auswehung offenbar größer gewesen als bei Bildung der Jüngeren.

Trockenes Klima: Während der Auswehung der Älteren Äolianite hat ein sehr trockenes Klima geherrscht. Eine zusammenhängende Vegetationsdecke kann nicht vorhanden gewesen sein, weil diese ein Anwehen der Karbonat-Sande bis auf große Höhen kaum zugelassen hätte.

Das Klima änderte sich offenbar mit Beginn der Umlagerungen der angewehten Alteren Aolianite. Oft starke Durchwurzelungen der Karbonatsande, Bodenbildungen und deutliche Anzeichen von Verschwemmungen und Verspülungen zeigen eine Zunahme der Niederschläge und Vegetationsdichte an.

Bei den Jüngeren Äolianiten handelt es sich um ehemalige Küstendünen, die nicht wesentlich in das Landesinnere hineinreichen. Ihre Entstehung setzt keine besondere Trokkenheit voraus; nähere Angaben zum Klima während ihrer Anwehung lassen sich nicht machen.

Eine Heraushebung von Ibiza als Voraussetzung für die Entstehung und weite Verbreitung der Alteren Äolianite wird nicht angenommen. 
Eine solche Auffassung war von Fallot (1922: 192) mit dem Hinweis begründet worden, daß im westlichen Mittelmeer Dünensande üblicherweise nur bis zu Höhen von $30-40 \mathrm{~m}$ über den Meeresspiegel aufgeweht werden könnten. Das würde bedeuten, daß während der Bildung der topographisch hochgelegenen Vorkommen der Alteren Äolianite die Differenz zwischen Ablagerungsort und Meeresspiegelniveau wesentlich geringer gewesen sein müßte als in der Gegenwart. Dieses könnte durch eine stetige Heraushebung der Insel während der Ablagerung der Älteren Äoliante erklärt werden, will man nicht einen zeitweise um 150 m (oder mehr) höheren Meeresspiegelstand als heute annehmen.

Der Hinweis von FALLOT berücksichtigt nicht, daß vor und in Ibiza Karbonat-Sande in ungewöhnlich großen Mengen für einen Windtransport zur Verfügung gestanden haben, so daß eine Aufwehung in Höhen bis zu mehr als $250 \mathrm{~m}$ über den Meeresspiegel sehr wohl vorstellbar ist. Im übrigen sind von uns - wie in Kap. 3.1 ausgeführt wurde - an keiner Stelle Ibizas in den Alteren Äolianiten eindeutige Hinweise auf Strandbildungen gefunden worden, die man bei einer Heraushebung der Insel erwarten sollte.

\section{Beziehungen zwischen der Morphogenese der Inseln und den Äolianiten}

\subsection{Fußflächen}

Das Relief der Insel Ibiza ist nur wenig ausgeprägt und wenig differenziert. Die ältesten erhaltenen Formenelemente sind zweifellos ausgeprägte Felsfußflächen (Pedimente) in Form von knicklosen Schnittflächen, die um wenige Grad geneigt sind, über dem gefalteten Untergrund aus Kalksteinen, fallweise auch Mergelsteinen des Mesozoikums. Diese Fußflächen umgeben die Bergländer, aber auch kleine isolierte Hügel an allen Seiten und setzen an ihnen mit weiten konkaven Hangprofilen an. Charakteristischerweise fehlen den Fußflächen alle Anzeichen einer Mehrphasigkeit in Form von Stufen oder Stockwerkbau, wie er vom spanischen Festland beschrieben wurde (Mensching 1964; Wenzens 1977; Gehrenkemper 1978). Diese alten Pedimente mit einer Ausdehnung bis zu einigen Kilometern sind von solch einheitlicher Form, daß während der gesamten Zeit ihrer Entstehung ein nahezu ungestörtes Basisniveau im Randbereich der Insel bestanden haben muß. Da die Böschungen überall meerwärts gerichtet sind, dürfte dafür nur ein quasi konstanter Meeresspiegel infrage kommen, der wenig unterhalb des heutigen gelegen haben dürfte. Wahrscheinlich setzen sich die Fußflächen fort in den ausgedehnten Flachwasserpartien um die Insel und sind lediglich im Bereich der heutigen Kliffe durch flachere Schorren mit Feinsedimenten und abrasiv angelegten Steilwände unterbrochen.

Die Genese der Fußflächen erfordert einen langen Zeitraum auch tektonisch ungestörter terrestrischer Entwicklung unter akzentuierten ariden Bedingungen. Die oft mächtige und vielgliedrige quartäre Überdeckung auf distalen Teilen der Pedimente deutet dabei auf eine i. w. präquartäre Anlage hin in einem auch klimatisch-morphologisch sehr gleichförmigen Zeitabschnitt. Dieser läßt sich wenigstens grob eingrenzen: die jüngsten Ablagerungen des Tertiärs (Konglomerate des Miozäns) sind in jedem Falle älter als die Fußflächen. Da pliozäne Sedimente auf Ibiza vollständig fehlen, ist für diesen Zeitraum eine Festlandphase anzunehmen, in der wahrscheinlich die Fußflächen ausgebildet wurden. Dafür ist ein wesentlich arideres Klima als heute zu vermuten. Die Vollkommenheit der Ausbildung und die große Verbreitung der Fußflächen sowie ihre gegenwärtige Lage deuten darauf hin, daß der Bildungszeitraum ebenso langanhaltend wie morphodynamisch recht einheitlich war und daß nachträglich keine differenzierte Tektonik die Insel erfaßt hat.

An einer ganzen Reihe von Kliffabschnitten (bes. im S Ibizas) ist nun zu beobachten, $\mathrm{da}$ auf die Phase der Pedimentbildung eine weitere der intensiven chemischen Verwitterung der Fußflächen folgte. Entsprechende Sedimente sind in situ besonders dort mehrere Meter mächtig erhalten, wo kleine Aufragungen distale Fußflächenbereiche von der Beeinflussung durch starke Sedimentanlieferung von höherem Hinterland geschützt haben (z. B. an der Punta Embarcado im Südteil der Cala Conta, am Cabo Blanch NW San 
Antonio Abad). Die Spuren dieser chemischen Tiefenverwitterung zeigen sich in autochthonen Rotlehmen sowie in einer viele Meter tief in Klüfte und Schichtfugen eingreifenden kaolinartigen Zersetzung selbst der Kalkgesteine.

Keinesfalls ist jedoch diese chemische Tiefenverwitterung als Ursache für die Flächenbildung i.S. einer Rumpfflächengenese anzusehen, sondern sie setzt immer an bereits existierenden älteren Schrägflächen an. An vielen Stellen sind diese tonig-schluffigen Verwitterungsprodukte durch spätere Schuttanlieferung von den Hügelländern her beseitigt worden, ohne daß dabei eine Überprägung oder Weiterbildung der Felsfußflächen stattgefunden hätte.

Insgesamt liegen damit Belege dafür vor, daß einer ausgedehnten gleichartigen Phase arider Dynamik mit Schuttproduktion, Schutttransport und Pedimentbildung eine solche der chemischen Tiefenverwitterung folgte, die gegenüber den heutigen Verhältnissen wahrscheinlich wärmer, gleichförmiger und sicherlich erheblich feuchter gewesen sein muß. Alle diese Formen und Ablagerungen sowie auch die im folgenden zu beschreibenden Täler sind sicher älter als die ältesten Ablagerungen von Äolianiten auf Ibiza.

\subsection{Talformen}

Auf die Fußflächenentwicklung und die Phase der chemischen Verwitterung folgte eine Zeitspanne der Talbildung, rückschreitend um einige $100 \mathrm{~m}$ bis kaum $2 \mathrm{~km}$ in die Fläche eingreifend und diese kaum zerlegend. Die Täler sind wenig verzweigt gewesen, nur um $20-50 \mathrm{~m}$ tief und kerbenartig ausgebildet. Sie waren auf einen um $20-30 \mathrm{~m}$ tieferen Meeresspiegel als die Fußflächen selbst eingestellt. Nur im Nordteil von Ibiza kommen größer dimensionierte Täler vor. Normalerweise enden die Täler mit regelrechten Kerbensprüngen noch auf den Pedimenten, ohne rückschreitend die Sattelpartien oder Bergflanken erreicht zu haben. Heute sind viele dieser Kerbtäler durch Einlagerung von Aiolianiten wieder verfüllt (Abb. 2).

Die relative Gleichförmigkeit, der geringe Verzweigungsgrad und die Kürze dieser Täler kann dreierlei Ursachen gehabt haben: eine begrenzte Zeitspanne eines für linienhaften Abfluß geeigneten Klimas (die direkt vorhergehende Phase war allerdings besonders feucht und zeigt keine prägnante Talbildung), eine eustatisch bedingte Absenkung des Basisniveaus (wahrscheinlich zu Beginn des Pleistozäns) oder auch eine tektonische geringe und ruckartige Heraushebung zur gleichen Zeit, die einen Zerschneidungsimpuls der Fußflächen ausgelöst hat. Die letztgenannte Ursache dürfte jedoch wenig wahrscheinlich sein, weil sich für ganz Ibiza eher eine langandauernde Absenkung seit der Fußflächenbildung belegen läßt (s. u.).

Auch diese Talbildungsphase zeigt an, daß während des Quartärs auf Ibiza oberflächliche Abtragung, Verwitterung und Abfluß bei weitem vorherrschten und trotz des Untergrundes aus karbonatischen Gesteinen kaum Verkarstungen zu beobachtungen ist. Die teils sehr mächtige und vielgliedrige Verfüllung etlicher der Täler mit alten Schuttsedimenten (Kap. 8.3) zeigt außerdem an, daß ihre Ausbildung bereits im älteren oder ältesten Quartär abgeschlossen gewesen sein muß.

Sicher ist weiterhin, daß diese Täler bereits vollständig ausgebildet waren, als erstmalig und großflächig die Alteren Äolianite auf- und eingelagert wurden. Durch diese Verfüllung sind die Täler relativ kurzfristig außer Funktion gesetzt worden. Die Dauer der ersten Ablagerungsphase der Äolianite muß nicht unbedingt lang gewesen sein jedenfalls fehlen zunächst alle Hinweise auf Unterbrechungen der äolischen Sedimentation.

Die mit Äolianiten und Schutt- sowie Bodensedimenten verfüllten und plombierten Täler sind mehrfach, aber nicht überall, durch vom Meer her rückschreitende Erosion in 
Kerben wieder aufgedeckt worden, wobei jedesmal das Basisniveau eher tief gelegen hat. Erneute Einlagerung von Älianiten hat dann die Täler wiederum plombiert, zumal sie nur ganz geringe Längen von wenigen $100 \mathrm{~m}$ erreicht haben. Im Holozän scheint die Zerkerbung im Zuge alter Täler dagegen wieder etwas intensiviert worden zu sein, wobei wahrscheinlich der flächenhafte Eingriff des Menschen in den Naturhaushalt beschleunigend auf die Abflußvorgänge gewirkt hat. Obwohl die erste Talgeneration in den meist harten Kalksteinen, die späteren dagegen nur in mäßig verfestigten klastischen Sedimenten angelegt wurden, wurde in keinem Fall - weder nach Länge, Laufentwicklung noch Zerschneidungstiefe - die Qualität der ersten Talbildung nochmals erreicht. Einige Täler sind dagegen über einen längeren Zeitraum hinweg durch Schuttsedimente aufgefüllt worden. Ihre Querprofile finden sich aufgeschlossen an den Kliffen (z. B. Cala Truya). Durch die Verfüllung sind sie wieder zu Teilen der Fußflächen (jetzt der Glacis) geworden (Abb. 8).

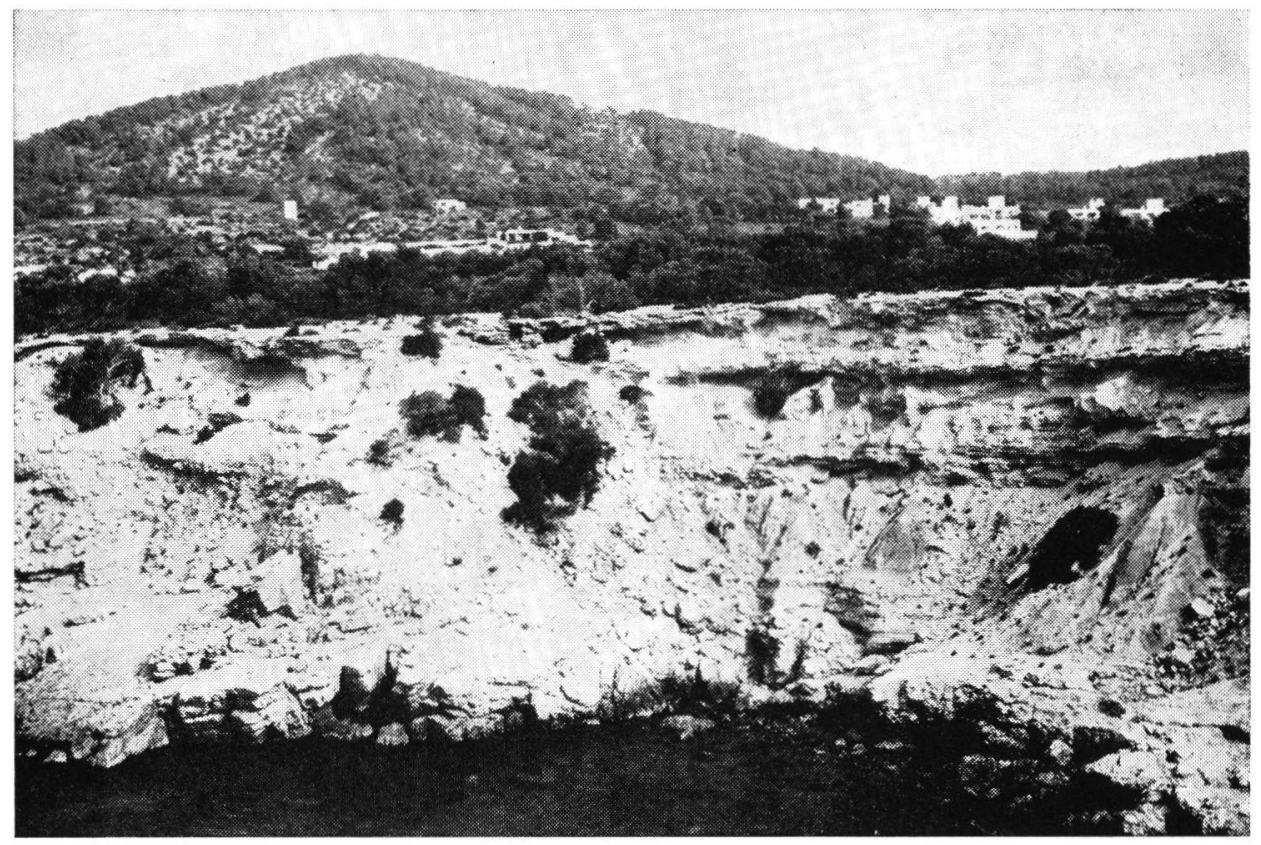

Abb. 8: Glacis-Fläche mit wieder verfülltem früheren Tal: Uber Kalksteinen der Kreide-Zeit an deren Oberseite Strandgerölle und Fossilreste des Miozäns - liegen Schuttablagerungen, die ein pleistozänes Tal plombiert haben. Glacis-Fläche von Kalkkrusten gebildet. Cala Truya in W Ibiza.

\subsection{Schuttdecken, Böden und Bodensedimente}

Während die stärker konkaven Hangbereiche an den Bergflanken ebenso wie deren Hänge selbst meist schuttfrei zutage treten, ist in Richtung zu den distalen Teilen der Fußflächen und den unteren Talabschnitten eine zunehmende Überdeckung durch SchuttSedimente verschiedener Art $\mathrm{zu}$ beobachten. Im Laufe der Zeit wurden so die unteren Partien der Felsfußflächen in Schuttfußflächen - echte Glacis bzw. glacis d'accumulation im franz. Sprachgebrauch - umgewandelt. Anscheinend hat sich diese Überdeckung rückschreitend auch auf höhere Pedimentbereiche ausgedehnt. Gute Einblicke in die stratigra- 
phischen Verhältnisse dieser Glacisschuttkörper geben wiederum die Kliffaufschlüsse (vgl. z. B. auch Rohdenburg \& SAbelberg 1973).

Sie zeigen im Groben einen zyklischen Aufbau mit Alternieren von Grobschuttlagen und Lehmähnlichen Bodenrelikten oder Bodensedimenten vom Typ der terra rossa. Gut entwickelte und ungestörte lamellenartige $\mathrm{C}_{\mathrm{Ca}}$-Horizonte an der Basis solcher Straten scheinen dabei gute Indikatoren tür Bodenbildungen in situ zu sein, es überwiegen jedoch die Bodensedimente bei weitem. In etlichen Kliffprofilen sind zwischen die Schutt- und Bodendecken noch mehrfach Äolianite eingeschaltet, entweder in primärer Lage mit guter Schrägschichtung oder stark verspült und dann charakteristischerweise meist mit Gehäusen von Helix angereichert.

Eine Gleichartigkeit der Sedimentabfolge von Profil zu Profil ist weder in der Anzahl der Straten, ihrer Mächtigkeit noch nach den darin vorkommenden autochthonen Bodenbildungen festzustellen. Dagegen ist zu beobachten, daß die Mächtigkeit der Straten ab- und ihre Zahl stark zunimmt in Kichtung auf immer entferntere Bereiche der Fußflächen (z. B. in der Cala Yondal). Aber auch dort fehlen durchlaufende Horizonte, und die Situation deutet eher auf eine mehrfache Umlagerung von Hangschuttsedimenten hin. Je länger deren Transportwege wurden bzw. je häufiger sie umgelagert wurden, um so mehr hat die Zurundung der Gerölle zugenommen, was z. T. zu einer fälschlichen Ansprache als Strandschotter geführt hat (s. Kap. 8.5).

Insgesamt ist aus den Kliffprofilen folgendes abzuleiten: Das Vorkommen von mehreren, getrennt übereinander liegenden Aolianit-Körpern weist auf einen mehrfach in unmittelbarer Nähe gelegenen Meeresspiegel hin, die Kappung der Äolianit-Körper (Abb. 4) in Verbindung mit den zwischengeschalteten Schuttlagen zeigt wiederholte morphodynamische Aktivität (im Sinne von RoHDENBURG 1970) an, die autochthonen Bodenbildungen innerhalb der Profile belegen Phasen morphodynamischer Stabilität. Welche Zeitabschnitte innerhalb des Quartärs durch diese Zyklen jeweils angezeigt werden, läßt sich vorerst nicht eindeutig angeben.

\section{4. „Kalkkrusten“}

„Kalkkrusten" oder "Caliche" sind in allen sedimentbedeckten Teilen von Ibiza und Formentera eine nahezu ubiquitäre Erscheinung. Ihre Mächtigkeit schwankt zwischen einigen Millimetern und über $1 \mathrm{~m}$, Lamellenkrusten und kompaktere Inkrustierung von Sanden und Schutten kommen nebeneinander vor. In homogeneren Substraten (etwa den Aolianiten) ist gut zu erkennen, daß es sich bei den „Kalkkrusten“ um $\mathrm{C}_{\mathrm{Ca}}$-Horizonte von Bodenbildungen handelt. Ihr Auftreten an der Oberfläche, wo sie in küstennahen Teilen Ibizas weitflächig einen extrem scherbigen, klingenden Schutt bilden, ist auf spätere Abtragung der oberen Bodenhorizonte zurückzuführen. Eine solche Abtragung und Zerlegung von „Kalkkrusten“ zu scherbigem Schutt hat im Verlaufe des Quartärs mehrfach stattgefunden, wie etliche, nahezu allein aus Calichetrümmern bestehende Grobschutthorizonte in den Kliffprofilen belegen.

Insgesamt sind die „Kalkkrusten“ die widerstandsfähigsten Elemente in den Abfolgen quartärer Sedimente; sie ragen daher als Gesimse aus den Kliffwänden heraus. Das gilt insbesondere für die jüngste und oberste Kruste an der Kliffkante, die meist von außerordentlicher Dicke (bis zu $2 \mathrm{~m}$ ) und Festigkeit ist. Die Oberfläche der heutigen Glacisbereiche wird ebenso von ihr gebildet wie die Basis über dem Anstehenden in den meisten Äolianit-Aufschlüssen.

\subsection{Pleistozäne Strandterrassen und -ablagerungen}

Frühere Arbeiten zur Geologie der Insel Ibiza und Formentera (SolÉ-SABaris 1962; Igme 1970) erwähnen marine pleistozäne Abrasionsterrassen, gelegentlich mit Strandschotter darauf, aber immer ohne kennzeichnende Fauneninhalte. Die Niveaus sollen sich bei $2-3 \mathrm{~m}, 5-6 \mathrm{~m}$ und $25-30 \mathrm{~m}$ häufen und werden in den Tyrrhenzyklus (Paläobis Neotyrrhen) gestellt. Eine Überprüfung dieser Angaben im Gelände, aber auch Kon- 
trollbegehungen an bisher nicht beschriebenen Küstenabschnitten Ibizas zeigten jedoch das völlige Fehlen von Spuren ehemaliger Meeresspiegelstände oberhalb von NN, die dem Quartär zugeordnet werden könnten.

Die angebliche Abrasionsniveaus sind ausnahmslos unter quartärer Bedeckung in sehr verschiedenen Höhen ausstreichende Schnittflächen aus dem Pedimentierungsprozeß bzw. schichtparallele Absätze innerhalb annähernd horizontaler Gesteinsserien. In einem Falle (Cala Truya), wo in verschiedenen Höhen am Kliff tatsächlich auf den Schnittflächen Ostreen und Seeigel (Clypeaster altecostatus) gefunden wurden, handelt es sich um einen wieder aufgedeckten Transgressionsstand des miozänen Meeres, der dort (ebenso wie z. B. westlich des Cerro Lientrisca in Höhen von $120 \mathrm{~m}$ und $170 \mathrm{~m}$ sowie am Atalayasa bei $350-380 \mathrm{~m}$ ) sehr gut gerundete Strandschotter hinterlassen hat.

In allen Fällen fehlen die Belege für quartäre höhere Meeresstände völlig, sei es, daß auf den angeblichen Abrasionsflächen noch die Reste einer ehemaligen terrestrischen Tiefenverwitterung zu finden sind, sei es, daß die angeblichen Strandschotter darauf nichts weiter als durch fluvialen Transport zugerundete Gerölle darstellen, die aber — wie der Vergleich mit den extrem gut gerundeten Schottern am rezenten Strand belegt — nicht im Wellenbereich bearbeitet worden sind. Das völlige Fehlen von Bruchschill oder Makroresten in den angeblichen Strandablagerungen ist daher nicht verwunderlich. Wo Denudationshänge an Buchtflanken schuttfrei und steiler eintauchen, fehlen ebenfalls jegliche Anzeichen für ehemals höhere Meeresspiegelmarken an ihnen. Es ist jedoch nicht zu leugnen, daß die im Kliff unterschrittenen, in der Luft ausstreichenden alten Fußflächen aus der Ferne den Eindruck von ausgedehnten Abrasionsterrassen vermitteln können.

Damit ist sicher, daß der gegenwärtige Meeresspiegel seit dem Pliozän - d. h. seit Anlage der Pedimente - die höchste Lage an den Flanken Ibizas erreicht hat. Im Vergleich mit den übrigen Mittelmeergebieten und darüberhinaus bedeutet dies eine relative Absenkung der Insel, die allein im Quartär einen Betrag von ca. $150 \mathrm{~m}$ oder mehr, verglichen mit dem mediterranen Standard der quartären Terrassenhöhen, erreicht haben dürfte. Diese Absenkung ist wahrscheinlich kontinuierlich erfolgt, weil durch die zyklischen Vorkommen von Aolianiten als Stranddünen nachgewiesen ist, daß die interglazialen oder interstadialen Meeresspiegel jeweils recht nahe an die heutige Küste und den

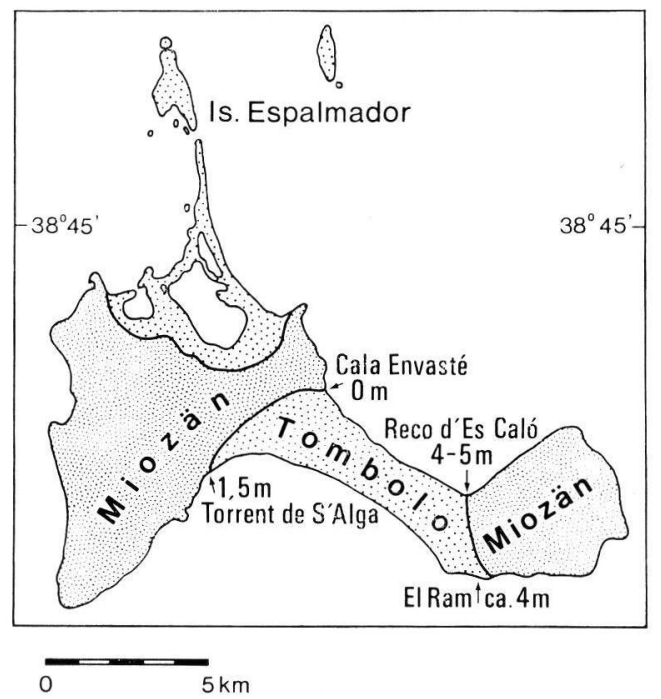

Abb. 9: Vereinfachte geologisch-morphologische Übersichtskarte von Formentera. Die Meter-Angaben beziehen sich auf die Höhenlage des neotyrrhenen Strandes. 
heutigen Meeresspiegel herangereicht haben. Das vermehrte Auftreten Jüngerer Äolianite in Richtung zur Südspitze von Ibiza und auf dem Inselarchipel in der Wasserstraße nach Formentera deutet zudem darauf hin, daß die Absenkung in diesen Bereichen im jüngeren Quartär nicht so ausgeprägt war bzw. hier allmählich ein Gebiet mit stabiler Höhenlage beginnt.

Auf Formentera selbst existieren jüngstpleistozäne Meeresspiegelmarken, die nur eine geringe Verstellung erfahren haben. Die Untersuchungen in Formentera wurden auf 4 Schlüsselstellen, nämlich je beide Seiten der Tombolowurzeln, welche die alten Inselkerne seit dem jüngeren Pleistozän verbinden, beschränkt. Im nördlichen Buchtwinkel am Westende des Tombolos (Cala Envasté) sind harte miozäne Kalksandsteine mit Muschelpflastern in einem senkrechten Kliff angenagt worden. Der Fußpunkt dieses Kliffes liegt kaum unter dem gegenwärtigen Meeresspiegel, wie an abrasiven Glättungsspuren zu erkennen ist. Im Bereich der Tombolowurzel wird dieser ältere Kliffuß zunächst von einer Schutthalde mit verlagerten dunklen Böden (Tirse) verhüllt und anschließend durch aufgewehten Dünensand (inzwischen verfestigt) weit hinauf maskiert. Von diesem Äolianit sind die obersten Schichten verschwemmt und von geringer Bodenbildung gefärbt worden, während die Oberfläche eine lückenhafte Kalkkruste trägt. Am Fußpunkt des verschütteten Kliffes muß sich demnach der letzte noch dem Pleistozän zuzuordnende Höchststand des Meeresspiegels befunden haben. Dieses ältere Kliff wird abseits des Tombolos heute wieder bearbeitet, ist jedoch noch nicht wesentlich weitergeformt oder zurückgelegt worden.

Das läßt sich auch an der gegenüberliegenden südlichen Tombolowurzel erkennen. Dort, in der Bucht zwischen Torrent del Alga und Torre Catalá, finden sich Reste einer schmalen Brandungsleiste (bis zu etwa $5 \mathrm{~m}$ Breite, $1,5 \mathrm{~m}$ über dem Meeresspiegel) teilweise bedeckt von roter Breccie oder wiederum von Äolianiten.

Die Befunde an der östlichen Tombolowurzel liefern etwas andere Bilder, obwohl es sich unzweifelhaft um Spuren des gleichen Meeresspiegelstandes handelt. Im nordexponierten Buchtwinkel bei Reco d'Es Caló kann man eine Hohlkehle in ca. 4-5 m Höhe an den Steilflanken des alten Inselkernes weiterhin verfolgen. Sie verschwindet zum Tombolo hin unter Äolianiten, die hier eine Mächtigkeit von mehr als $60 \mathrm{~m}$ erreichen. Die geringe Überprägung dieser Äolianite durch Bodenbildungen und fehlende Kappung durch weitere Meeresspiegelstände weisen wiederum darauf hin, daß die Hohlkehle einem sehr jungen pleistozänen Meeresspiegelstand angehören muß.

An der südwärts geöffneten Bucht, also dem gegenüberliegenden Tombolobereich am Caló d'Es Mort, lassen sich die Befunde am eindeutigsten zuordnen. Hier ist zunächst nach S hin ein hohes, durch junge Tafoni stark zergliedertes Kliff in jungpleistozänen und holozänen Äolianiten zu verfolgen. Darin streichen mehrfach in verschiedenen Höhen tirsoide Böden aus, die insgesamt auf eine Dreiteilung des alten Dünenkörpers hinweisen. Etwa $1 \mathrm{~km}$ SE der letzten Hotelanlage bei El Ram taucht allmählich am Kliffuß eine immer wieder unterbrochene Abrasionsplattform auf, die schließlich nach einem weiteren Kilometer bis über $50 \mathrm{~m}$ Breite und um $3 \mathrm{~m}$ Höhe erreicht. Sie ist als Kappungsfläche in Äolianiten angelegt und zeigt neben deutlichen Spuren einer flachen subkutanen Verkarstung auch Klüfte in Richtung der Hauptbeanspruchungslinien von Formentera (besonders NE/SW-verlaufend). Diese Abrasionsfläche verschwindet unter überlagernden Äolianiten, so daß der Fußpunkt eines zugehörigen Kliffes und damit die alte Meeresspiegelmarke nicht mit letzter Sicherheit zu bestimmen ist. Sie dürfte jedoch kaum höher als $+4 \mathrm{~m}$ liegen und damit mit der Hohlkehle an der anderen Seite des Tombolos korrespondieren. Den endgültigen Beweis für eine marine Anlage der Abrasionsfläche liefern die durchgehend erhaltenen litoralen Ablagerungen jenes Meeresspiegelstandes, die in Form einer etwa 0,5 m mächtigen stark fossilführenden Schicht erhalten sind (Abb. 10 und 11). 


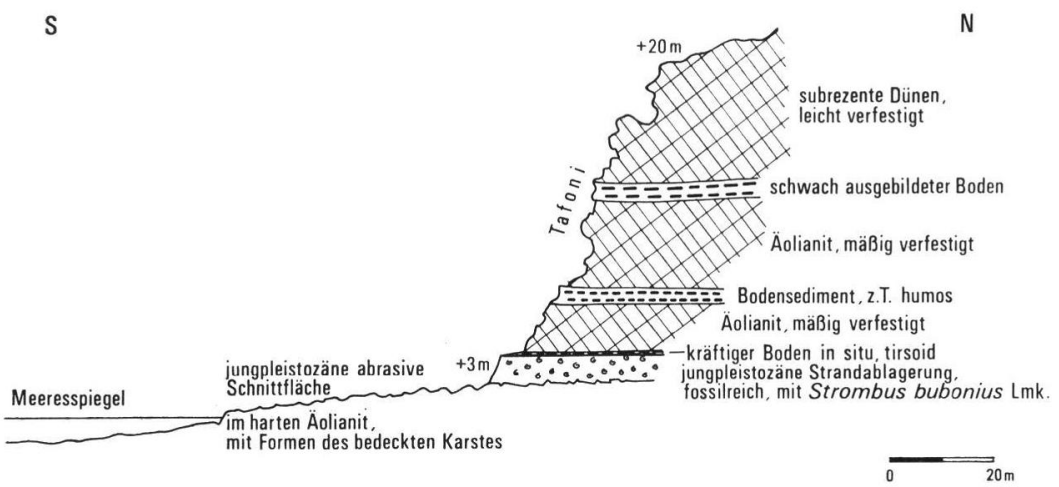

Abb. 10: Küstenprofil in SE Formentera: Strandbildung des Neotyrrhens in Abfolge von gegliederten Äolianiten.

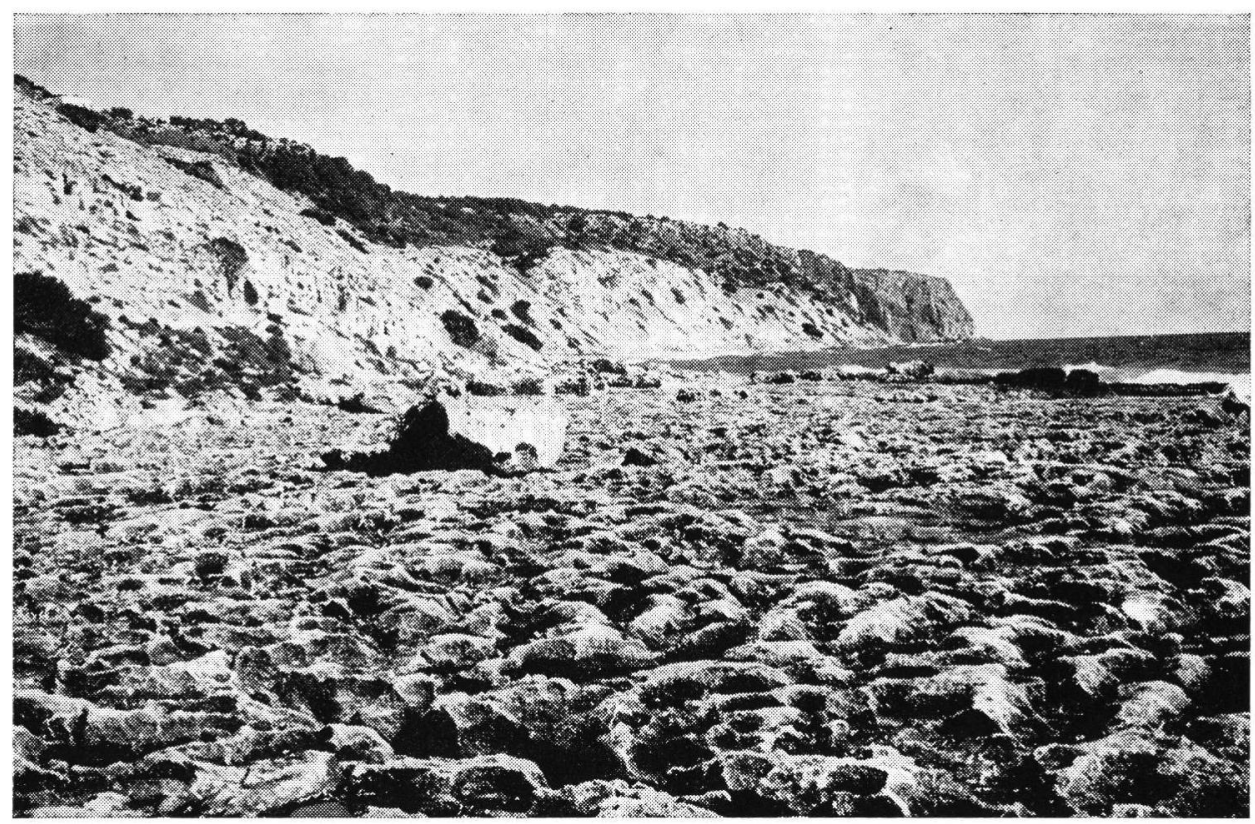

Abb. 11: Neotyrrhene Abrasionsfläche in Jüngeren Aolianiten mit deutlichen Verkarstungsspuren, von weiteren Äolianiten überlagert. Vgl. Abb. 10. W El Ram in SE Formentera.

Eine flüchtige Aufsammlung von Makroresten auf nur $0,5 \mathrm{~m}^{2}$ erbrachte die folgenden Arten (det. D. Kelletat):

S c a ph o p od a : Dentalium entalis L., Dentalium vulgare DA Costa.

E ch in oidea: (Reste).

L i th o th a m n i u m (zahlreiche Gerölle bis zu Faustgröße).

B iv a lvi a: Arca barbata L., Arca noae L., Cardium edule L., Chama gryphoides L., Glycimeris glycimeris (L.), Glycimeris violascens (Lam.), Lima hians (GMelin), Lima lima (L.), Pecten jacobaeus L., Pitaria cbione (L.) 
Gastropoda: Astraea rugosa (L.), Bittium reticulatum DA Costa, Calliostoma zizyphinum (L.), Ceritbium vulgatum BRug., Columbella rustiva (L.), Diodora italica (Defrance), Dolium galea (L.), Fissurella costaria (Lam.), Monodonta turbinata (BorN), Murex trunculus L., Natica millepunctata Lama, Natica lactea Guilding, Patella aspera Lam., Patella coerulea L., Strombus bubonius Lam., Thais haemastoma (L.), Trivia (Trivia) europaea mediterranea (RIsso), Vermetus arenarius (L.), Vermetus triquiter BIVoNa;

Glycimeris sp. sehr groß und zahlreich, dagegen selten Spondylus gaederopus L., nicht beobachtet Cladocora cespitosa (L.) und Patella ferruginea GMelin.

Alle Arten leben heute noch im Mittelmeer mit Ausnahme von Strombus bubonius Lam. als Leitfossil des tyrrhenen Zyklus, hier sicherlich des letztpleistozänen Hochstandes und damit des Neotyrrhen.

Von Mallorca hatte SolÉ SABARIS (1962) mehrere Fundpunkte von Strandablagerungen mit Strombus bubonius in vergleichbaren Niveaus von $1,5-5 \mathrm{~m}$ ü. NN genannt und dem Neotyrrhen zugeordnet. Das Neotyrrhen wird heute meist mit dem Würm-Interstadial gleichgesetzt (vgl. z. B. HERForth \& Richter 1979: 2).

Bemerkenswert ist, daß die Aolianite über den neotyrrhenen Strandablagerungen keine regressiven Bildungen beim Rückzug des Meeres vom damaligen Hochstand waren, sondern daß zunächst eine intensive Bodenbildung direkt auf den Strandsedimenten ansetzte. Sie hat stellenweise zu starker Korrosion der Mollusken geführt; vom Typ her ist der Boden ein sehr gut entwickelter Tirs. Die darüber folgende Dünengeneration ist erst bei einem weiteren Transgressionsvorgang aufgesetzt worden, wiederum in unmittelbarer Nähe eines Meeresspiegels, der jedoch die heutige Höhe nicht mehr ganz erreicht hat. Dieser Vorgang fand nach dem Neotyrrhen in mehrfacher Widerholung statt, woraus sich jeweils relativ hohe eustatische Meeresspiegelstände innerhalb des Spätwürms (Interstadiale) ableiten.

Auch im Verlaufe der holozänen Transgression ist wieder eine kräftige Dünenbildung zu beobachten. Diese Dünen zeigen - wie am Strand von Mitjorn im Süden Ibizas bereits Spuren von Verfestigung und partienweise lückenhafte Caliche-Bildungen. Insgesamt ist sowohl am Tombolo von Zentral-Formentera wie auch an der weit nach $\mathrm{N}$ (gegen Ibiza) gerichteten Inselspitze von Formentera (die ebenso ein unvollständiger bzw. im Postglazial abrasiv wieder zerstörter Tombolo nach Espalmador ist) zu erkennen, daß beide sukzessiv durch die seitliche Anlagerung immer neuer Dünenzüge bei kaum tieferen Meeresspiegeln als heute angelegt wurden. Die rasche Verfestigung dieser Dünen hat zur Stabilisierung der Formen beigetragen. Dagegen fehlen auf Ibiza und Formentera die sonst in dieser Breitenlage anzutreffenden Beachrock-Bildungen völlig.

\section{Entwicklungsgeschichte der Inseln im Jungpliozän und Quartär}

Aufgrund der im vorhergehenden Text gemachten Ausführungen läßt sich die Entwicklungsgeschichte von Ibiza im jüngeren Pliozän und Quartär in folgendem Schema zusammen (s. S. 132):

Seit dem Pliozän (Zeit der Pediment-Bildung) hat sich Ibiza insgesamt abgesenkt, wobei zwischenzeitlich mehrere eustatische Schwankungen des jeweiligen Meeresspiegels anzunehmen sind.

Für Formentera ist dagegen keine Absenkung im jüngeren Pleistozän und Holozän abzuleiten; die Insel verhält sich in diesem Zeitabschnitt im wesentlichen stabil. Der strukturelle Unterschied im geodynamischen Verhalten zwischen beiden Nachbarinseln, auf den von mehreren anderen Autoren hingewiesen worden ist (vgl. besonders die Übersicht in Rios 1978: Fig. 1 und 10), besteht also bis in das Holozän hinein. 


\begin{tabular}{|c|c|c|c|c|}
\hline Zeit & Prozesse/Ablagerungen & $\begin{array}{l}\text { Klima im } \\
\text { Vergleich } \\
\text { zum heutigen }\end{array}$ & $\begin{array}{l}\text { Stand des } \\
\text { Meeresspiegels }\end{array}$ & $\begin{array}{l}\text { (tektonische) } \\
\text { Vertikal- } \\
\text { bewegungen }\end{array}$ \\
\hline Holozän & $\begin{array}{l}\text { Bodenabspülung, } \\
\text { teilweise Talbildung, } \\
\text { Bildung v. Küstendünen }\end{array}$ & & $\begin{array}{l}\text { ansteigend } \\
\text { bis } 0 \mathrm{~m}\end{array}$ & $\begin{array}{l}\text { Absenkung } \\
\text { andauernd }\end{array}$ \\
\hline Würm & $\begin{array}{l}\text { Anwehung der } \\
\text { Jüngeren Äolianiten } \\
-------- \\
\text { unterbr. v. Boden- } \\
\text { bildungen }\end{array}$ & $\begin{array}{l}\text { trockener (?) } \\
------ \\
\text { feuchter }\end{array}$ & $\begin{array}{l}\text { mehrfach } \\
\text { nahe } 0 \mathrm{~m} \\
------ \\
\text { niedriger }\end{array}$ & \multirow[t]{2}{*}{$\begin{array}{l}\text { schwache } \\
\text { Absenkung }\end{array}$} \\
\hline & $\begin{array}{l}\text { Verschwemmung und } \\
\text { Umlagerung der } \\
\text { Alteren Äolianite; } \\
\text { Schuttdecken, } \\
\text { Bodenbildungen }\end{array}$ & $\begin{array}{l}\text { Mehrfacher } \\
\text { Wechsel zwischen } \\
\text { trockener und } \\
\text { feuchter }\end{array}$ & $\begin{array}{l}\text { Oszill. zw. Regr. } \\
\text { und Transgres- } \\
\text { sionen, immer } \\
\text { niedriger als } \\
\text { heute }\end{array}$ & \\
\hline \multirow[t]{2}{*}{$\begin{array}{l}\mathrm{ab} \\
\text { Emilianum }\end{array}$} & $\begin{array}{l}\text { Anwehung der } \\
\text { Älteren Äolianite }\end{array}$ & $\begin{array}{l}\text { erheblich } \\
\text { trockener }\end{array}$ & $\begin{array}{l}\text { ca. } 5-50 \text { m unter } \\
\text { dem heutigen }\end{array}$ & $?$ \\
\hline & Kerbtalbildung & feuchter & $\begin{array}{l}\text { ca. } 30-40 \mathrm{~m} \text { un- } \\
\text { ter dem heutigen }\end{array}$ & geringe Hebung? \\
\hline \multirow{2}{*}{ 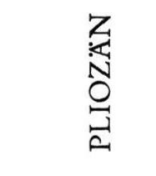 } & $\begin{array}{l}\text { Rotlehm-Bildung, } \\
\text { Kaolinisierung }\end{array}$ & erheblich feuchter & $\begin{array}{l}\text { unter dem } \\
\text { heutigen }\end{array}$ & \multirow{2}{*}{$\begin{array}{l}\text { stabil (?) } \\
\text { stabil }\end{array}$} \\
\hline & $\begin{array}{l}\text { Entstehung der } \\
\text { Felsfußflächen }\end{array}$ & trockener & $\begin{array}{l}\text { weniger unter } \\
\text { dem heutigen }\end{array}$ & \\
\hline
\end{tabular}

\section{Liste Probenpunkte}

(Proben 1-22 und I/II: Ibiza, 25: Formentera; vgl. Abb. 1 und 9)

1 : Äolianite, schräggeschichtet; Taleinschnitt im Grubengelände ca. $1 \mathrm{~km} \mathrm{SE} \mathrm{Cala} \mathrm{d'Hort,}$ $110 \mathrm{~m}$ ü. NN

3 a: Aolianite, umgelagert; Grube N-Hang Cerro Llentrisca, $250 \mathrm{~m}$ ï. NN

4 a: Aolianite, horizontal geschichtet; Hangendes der alten Steinbrüche an Küste ca. $800 \mathrm{~m} \mathrm{~W}$ Cerro Llentrisca, $20 \mathrm{~m}$ ü. NN

4 b: Aolinite, schräggeschichtet; Fp. wie vorher, $5 \mathrm{~m}$ ü. NN

6 : Rote Mergel in Schuttfolge; Küste Cala Truya, $4 \mathrm{~m}$ ü. NN (Abb. 8)

6 a: Rote Mergel in Schuttfolge; Fp. wie vorher, $20 \mathrm{~m}$ ü. NN (Abb. 8)

7 : Aolianite, horizontal geschichtet; N-Seite Flußtal an der Cala d'Hort, $25 \mathrm{~m}$ ü. NN

11 : Aolianite, schräggeschichtet; Basispartien große Grube ca. 2 km w San José, $130 \mathrm{~m}$ ü. NN (Abb. 2)

14 : Aolianite, schräggeschichtet; Basispartien Grube ca. $1 \mathrm{~km}$ SE Cala Bassa, $50 \mathrm{~m}$ ü. NN

15 : Aolianite, horizontal geschichtet; Küste Cala Conta, $3 \mathrm{~m}$ ü. NN

16 : Äolianite, schräggeschichtet; Küste Punta Embarcado, $20 \mathrm{~m}$ ü. NN

21 : Aolianite, schräggeschichtet; Basispartie Küste Cala Charraca, $1 \mathrm{~m}$ ü. NN

22 : Aolianite, schräggeschichtet; Mitte Küste Playa Mitjorn, 5 m ü. NN (Abb. 6)

22 b: Aolianite, Ausbildung wie vorher; Fp. 300 m weiter SE 
25 : Aolianite, horizontal geschichtet; W El Ram in Formentera, $5 \mathrm{~m}$ ü. NN (2 $\mathrm{m}$ über Neotyrrhen), Abb. 10 und 11

25 a: Aolianite, Ausbildung wie vorher; Fp. ca. $1 \mathrm{~km}$ W von Fp. 25

I: Äolianite, horizontal geschichtet; Grubengelände ca. $1 \mathrm{~km}$ E Cala d'Hort, $120 \mathrm{~m}$ ü. NN

II: Äolianite, horizontal geschichtet; Grube ca. $300 \mathrm{~m}$ SE Cala d'Hort, $60 \mathrm{~m}$ ü. NN.

\section{Schriftenverzeichnis}

Colalongo, M. L. (1968): Cenozone a Foraminiferi ed Ostracodi nel Pliocene e basso Pleistocene della serie del Santerno e dell'Appennino Romagnolo. - Comm. Medit. Neogene Strat., Proc. IV Sess., Bologna 1967, Giorn. Geol., 35: 29-61; Bologna.

- , Cremonini, G. \& Sartoni, S. (1978): La sezione stratigrafica di Rio Vendina (MessinianoPleistocene, Reggio Emilia). - Atti Soc. ital. Sci. nat. Museo civ. Stor. nat. Milano, 119: 61-76; Mailand.

FALlot, P. (1922): Étude géologique de la Sierra de Majorque. - Thèse, 480 S.; Paris und Liège (Béranger).

Gehrenkemper, J. (1978): Rañas und die Reliefgenerationen der Montes de Toledo in Zentralspanien. - Berliner Geogr. Abh., 29, 81 S.; Berlin.

Herforth, A. \& Richter, D. H. (1979): Eine pleistozäne tektonische Treppe mit marinen Terrassensedimenten auf der Perchorahalbinsel bei Korinth (Griechenland). - N. Jb. Geol. Paläont. Abh., 159: 1-13; Stuttgart.

Igme [Instituto Geológico y Minero de España] (1970): Mapa Geológico de España $1: 50$ 000, Bl. No. 772, 773, 798, 799, 824 und 825 m. Erl.; Madrid.

- (1972): Mapa Geológico de España 1:200000, Bl. 65-49 Ibiza-Mahon m. Erl.; Madrid.

KreJCI-Graf, K. (1961): „Versteinerte Büsche“ als klimabedingte Bildungen. - N. Jb. Geol. Paläont. Abh., 113: 1-22; Stuttgart.

Lentini, F. (1971): La sezione plio-pleistocenica di Pisticci sul bordo appenninico della Fossa Bradanica. - Atti Acc. Gioenia Sc. nat. Catania, ser. VII, 3: 109-192; Catania.

Mateu, G., Colom, G. \& Cuerda, J. (1979): Los Foraminíferos plio-pleistocenicos de la Isla de Cabrera (Baleares) y las condiciones paleoecologicas del antiguo Mar Balear. - Bol. Soc. Hist. Nat. Baleares, 23: 51-68; Palma/Mallorca.

Mensching, H. (1964): Die regionale und klimatisch-morphologische Differenzierung von Bergfußflächen auf der Iberischen Halbinsel (Ebrobecken-Nordmeseta-Küstenraum Iberiens). Würzburger Geogr. Arb., 12: 139-158; Würzburg.

Nolan, M. H. (1895): Structure géologique d'ensemble de l'Archipel Baléare (1). - Bull. Soc. Géol. France, 3e série, XXII: 76-91; Paris.

D’Onofrio, S. (1968): Biostratigrafia del Pliocene e Pleistocene inferiore nelle Marche. - Comm. Medit. Neogene Strat., Proc. IV Sess., Bologna 1967, Giorn. Geol., 35: 99-114; Bologna.

Rangheard, Y. (1969): Étude géologique des îles d’Ibiza et de Formentera (Baléares). - Thèse, 478 S.; Besancon.

Rios, J. M. (1978): The Mediterranean coast of Spain and the Alboran Sea. - in: NAIrN, A. E. M., Kanes, W. H. \& Stehli, F. G. (edit.): The Ocean Basins and Margins, $4 \mathbf{B}$ (The Western Mediterranean): 1-65; New York (Plenum).

Rohdenburg, H. (1970): Morphodynamische Aktivitäts- und Stabilitätszeiten statt Pluvial- und Interpluvialzeiten. - Eiszeitalter u. Gegenwart, 21: 81-96; O'́hringen/Württ.

- \& SAbelberg, U. (1973): Quartäre Klimazyklen im westlichen Mediterrangebiet und ihre Auswirkungen auf die Relief- und Bodenentwicklung. - Catena, 1: 71-180; Gießen.

Ruggieri, G. \& Sprovieri, R. (1977): A revision of Italian Pleistocene stratigraphy. - Geologica Romana, 16: 131-139; Rom.

SolÉ SABARIS, L. (1962): Le Quaternaire marin des Baléares et ses rapports avec les côtes méditerranéennes de la Peninsula Ibérique. - Quaternaria, 6: 309-342; Rom.

Spiker, E. T. N. \& Hannstra, U. (1935): Geologie von Ibiza (Balearen). — Géologie de la Méditerranée occidentale, III, (V, No. 3): 89 S.; Barcelona. 
